2020-05

\title{
Children's thermal comfort and adaptive behaviours; UK primary schools during non-heating and heating seasons
}

\section{Korsavi, Sepideh Sadat}

http://hdl.handle.net/10026.1/18019

10.1016/j.enbuild.2020.109857

Energy and Buildings

Elsevier BV

All content in PEARL is protected by copyright law. Author manuscripts are made available in accordance with publisher policies. Please cite only the published version using the details provided on the item record or document. In the absence of an open licence (e.g. Creative Commons), permissions for further reuse of content should be sought from the publisher or author. 


\title{
Children's thermal comfort and adaptive behaviours; UK primary schools during non-heating and heating seasons
}

\author{
Sepideh Sadat Korsavi*, Azadeh Montazami \\ Centre for the Built and Natural Environment (BNE), Faculty of Engineering, Environment and Computing, Coventry University, 3 Gulson Road, CV1 2JH, \\ United Kingdom
}

\section{A R T I C L E I N F O}

\section{Article history:}

Received 29 April 2019

Revised 20 December 2019

Accepted 12 February 2020

Available online 13 February 2020

\section{Keywords:}

Comfort temperature

Personal behaviours

Environmental behaviours

Primary Schools

Non-heating and Heating seasons

\begin{abstract}
A B S T R A C T
This paper aims to study children's thermal comfort and related Adaptive Behaviours in UK primary schools. The study was carried out in 32 naturally-ventilated classrooms during Non-Heating $(\mathrm{NH})$ and Heating $(\mathrm{H})$ seasons. Alongside collecting environmental data, a self-reported questionnaire and an observation form were employed to record children's thermal comfort and adaptive behaviours. From eight primary schools, 805 children aged 9-11 were surveyed and 1390 questionnaires were collected. Children's Thermal Sensation Votes (TSVs), Thermal Preference Votes (TPVs) and adaptive behaviours were compared against temperature offset from comfort temperature by EN $15251\left(\mathrm{~T}_{\text {diff }}=\mathrm{T}_{\mathrm{op}}-\mathrm{T}_{\mathbf{C}(\mathrm{CEN})}\right)$. Results suggest that children's thermal comfort $\left(\mathrm{T}_{\mathbf{C}(\text { children })}\right)$ is $1.9 \mathrm{~K}$ and $2.8 \mathrm{~K}$ lower than that for adults $\left(\mathrm{T}_{\mathbf{C}(\mathrm{CEN})}\right)$ during non-heating and heating seasons, respectively. Children have lower comfort temperature and higher sensitivity to temperature changes during heating seasons. This can be attributed to children's lower practice of personal behaviours and more consistent indoor conditions during heating seasons. The proportion of children engaged with personal behaviours is one-third lower during heating seasons. As indoor temperature goes above children's thermal comfort band, the proportion of children practising personal behaviours increases during non-heating seasons. Around $80 \%$ of window operation is carried out by teachers who have a higher comfort temperature than children.
\end{abstract}

(c) 2020 Elsevier B.V. All rights reserved.

\section{Introduction}

Due to climate change and rise in temperature, maintaining thermal comfort and reducing the risk of overheating in school buildings is becoming a major concern. Children are less resilient to adverse environmental conditions compared to adults, therefore, unacceptable environmental conditions affect them more significantly [1]. Reducing the risk of overheating and improving thermal environment in schools improve children's health, well-being, productivity, academic performance [1-16] and affects energy consumption [17-19]. It is shown that when classrooms' indoor temperature exceeds $23.9^{\circ} \mathrm{C}$ students' respiration rate increases, which provides conditions for some other diseases [20]. High temperatures cause sluggishness, tiredness [21], fatigue and reduced concentration $[22,23]$. It is shown that by reducing classroom temperature from $25^{\circ} \mathrm{C}$ to $20^{\circ} \mathrm{C}$, task speed of $10-12$ years old children increases by $2 \%$ per $1^{\circ} \mathrm{C}$ reduction in temperature [1]. Similarly, by $1{ }^{\circ} \mathrm{C}$ reduction in temperature, academic performance in stan-

\footnotetext{
* Corresponding author.

E-mail addresses: korsavis@uni.coventry.ac.uk_ (S.S. Korsavi),
} azadeh.montazami@coventry.ac.uk (A. Montazami). dardized tests improves by $2-4 \%$ [5,24]. In another study, performance of 11-12 years old children who were exposed to temperatures of $20^{\circ} \mathrm{C}$ and $30^{\circ}$ in the morning and afternoon was lower for higher temperatures and afternoon sessions [25]. Hence, concerns over thermal environment of primary school classrooms are growing [26].

To improve thermal environment in primary schools, it is vital to estimate comfort temperatures. According to Nicol, Humphreys and Roaf, (2012), "Comfort temperature or the neutral temperature is the temperature at which the largest number of participants will be comfortable" [18]. Comfort temperature is also defined as "the operative temperature at which the average person will be comfortable" [27]. According to ANSI/ASHRAE, (2013), "Thermal comfort is the condition of mind that expresses satisfaction with the thermal environment and is assessed by subjective evaluation" [28].

Comfort temperature varies in different studies under different climatic conditions around the world. In temperate climate of England, comfort temperature of 11-16 years old children is found $16.5^{\circ} \mathrm{C}$ during winter [29] and $19.1^{\circ} \mathrm{C}$ during summer [30]. Furthermore, comfort temperature of 7-11 years old children is found $20.5^{\circ} \mathrm{C}$ during spring [31]. In temperate climate of Korea, comfort temperature is found $22.1^{\circ} \mathrm{C}$ for $4-6$ years old children dur- 
ing spring [32]. In subtropical Australia, comfort temperature is found $24.2-24.5^{\circ} \mathrm{C}$ during winter [33] and $22.5^{\circ} \mathrm{C}$ during summer [17] for primary and secondary school children. In subtropical Taiwan, comfort temperature changes from 23 to $24^{\circ} \mathrm{C}$ in [34] and from 22.4 to $29.2^{\circ} \mathrm{C}$ in [35] for $11-17$ years old students during Autumn. In subtropical China, comfort temperature is reported at $20.9^{\circ} \mathrm{C}$ during summer [36]. In tropical locations, comfort temperature increases up to $26.8^{\circ} \mathrm{C}$ in Hawaii, US [37] and up to $28.8^{\circ} \mathrm{C}$ in Singapore [38]. In another study done in Iran with warm dry summers and cool winters, comfort temperature of 10-12 years old children is found $23.3^{\circ} \mathrm{C}$ during summer [39].

According to De Dear and Brager et al. (1998), differences in thermal comfort are related to occupants' physiological (acclimatization), psychological (expectations) and behavioural (clothing adjustments) adaptations [40]. Behavioural thermoregulation affects heat balance between human body and surrounding thermal environment $[38,40]$ through change in clothing layers, posture, metabolic rate, location or use of buildings' controls [18]. According to Nicol et al., "If a change occurs such as to produce discomfort, people react in ways that tend to restore their comfort" [18]. This reaction is either 'Personal Behaviour' with the occupants adapting to the building or 'Environmental behaviour' with the occupants adapting the building to suit their preferences. Adaptive Behaviours influence classrooms' environmental quality and school occupants' comfort significantly [41-44]. Therefore, adaptive behaviours should be facilitated in schools to achieve higher comfort levels for children [45].

Change in occupant behaviour as one of the actions to mitigate the risk of overheating is proposed by the UK National Adaptation Programme (NAP), 2018 [46]. Therefore, a clear understanding of both environmental and personal behaviours in schools is required under various climatic conditions. This study aims to investigate children's perception of classrooms' thermal environment and estimate their comfort temperature in relation to the existing adaptive comfort models. It also examines children's personal and environmental adaptive behaviours as a response to thermal discomfort during non-heating and heating seasons.

\section{Methodology}

This paper focuses on the relationship between thermal comfort and related adaptive behaviours when thermal environment is not within acceptable limits. The four main steps in this methodology are 1 . Selecting samples, 2 . Recording personal and environmental behaviours in relation to indoor environmental conditions, 3. Calculating comfort temperature and 4 . Overviewing recorded data.

\subsection{Sample selection}

To investigate adaptive behaviours without any bias, samples were selected with specific attention to the a) climate in which buildings were located, b) buildings and their neighbourhood, c) controls within the buildings and d) children's age range.

\subsubsection{Climate}

To reduce the biased impact of extreme climates on children's behaviour, schools need to be selected from a mild climate. Therefore, Coventry as the second-largest city in the West Midland with a mild climate according to Koppen classification [47] was selected. The study was carried out from mid-July 2017 until the end of May 2018 to include a wide range of weather conditions. Table 1 shows the range of environmental variables during heating and non-heating seasons. During school's occupancy (9:00-15:30), outdoor air temperature ranged from $0.7^{\circ} \mathrm{C}$ to $25.10^{\circ} \mathrm{C}$, relative humidity changed from $43 \%(\mathrm{RH})$ to $94 \%(\mathrm{RH})$ and air speed changed from $0.05 \mathrm{~m} / \mathrm{s}$ to $9.6 \mathrm{~m} / \mathrm{s}$, Table 1 . Outdoor variables were taken

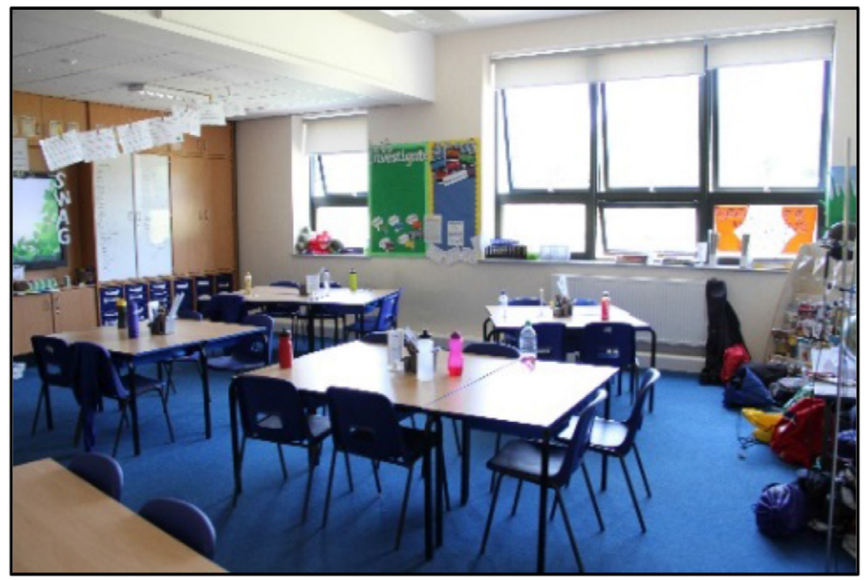

Fig. 1. Classroom providing high opportunities for children's window operation.

from local weather stations that were maximum 3 miles away from each field study site [48].

\subsubsection{Buildings}

To increase occupants' window operation, naturally-ventilated schools were selected in this study. Window opening can be restricted in naturally-ventilated schools that are located in neighbourhoods with a high background noise level [49,50]. To allow window operation without impairing acoustic comfort, schools were selected in quiet areas with a considerable distance to the main road. The regional Road Noise, LAeq $16 \mathrm{~h}$, is less than $55 \mathrm{~dB}$ in all selected schools according to England Noise Map Viewer [51]. This is the maximum acceptable external noise level that allows natural ventilation [52]. Furthermore, to not restrict window opening due to outdoor pollution, all schools were selected in areas with low Daily Air Quality Index (DAQI) according to Air pollution Forecast provided by the Met Office [53]. In total, 32 naturallyventilated classrooms in 8 primary schools were selected and studied during non-heating $(\mathrm{NH})$ and heating $(\mathrm{H})$ seasons, Table 2.

\subsubsection{Windows}

To categorize occupants' interaction with windows, schools with various window characteristics were selected after on-site visits and visual observations. Based on a comprehensive literature review on factors affecting window operation, selected classrooms were classified to ones with high and low opportunities for window operation. Review suggests that windows' ease of use [45,5456] and access and proximity to windows [45,57-61] facilitate windows' operation. Windows at low heights that are manuallyoperated and accessible by children can provide more opportunities for children's window operation [45]. Windows at different levels (high and low-level openings) and sizes (small and large) can provide thermal comfort and different kinds of ventilation $[45,50,62-65]$, therefore, they are operated more frequently to address different aspects of comfort.

Therefore, schools that provide high opportunities for window operation (Schools 1, 2 and 5) have many numbers of windows (8) in two different sizes and levels, have a low windowsill $(\leq 1 \mathrm{~m})$, are manually operated and are located within the length of the classroom. In this study, 18 classrooms provide low opportunities for window operation and 14 classrooms provide high opportunities for window operation, Table 2.

Figs. 1 and 2 show classrooms with high and low opportunities for window operation. Fig. 1 shows a classroom with openings at two different sizes and levels that can be operated manually alongside the length of the classrooms. Fig. 2 shows a classroom with 5 
Table 1

\begin{tabular}{llllll}
\multicolumn{2}{l}{ Outdoor variables in different seasons. } \\
\hline Seasons & Outdoor variables & Minimum & Maximum & Mean & Std. deviation \\
\hline \multirow{2}{*}{ Non-heating } & $\mathrm{T}_{\text {out }}\left({ }^{\circ} \mathrm{C}\right)$ & 9.6 & 25.1 & 17.5 & 3.7 \\
& $\mathrm{RH}(\%)$ & 43.0 & 94.0 & 73.0 & 15.5 \\
\multirow{3}{*}{ Heating } & $V(\mathrm{~m} / \mathrm{s})$ & .05 & 7.7 & 3.0 & 1.8 \\
& $\mathrm{~T}_{\text {out }}\left({ }^{\circ} \mathrm{C}\right)$ & .7 & 14.6 & 7.1 & 3.1 \\
& $\mathrm{RH}(\%)$ & 50.0 & 94.0 & 80.5 & 9.9 \\
& $V(\mathrm{~m} / \mathrm{s})$ & .05 & 9.6 & 2.8 & 1.9 \\
\hline
\end{tabular}

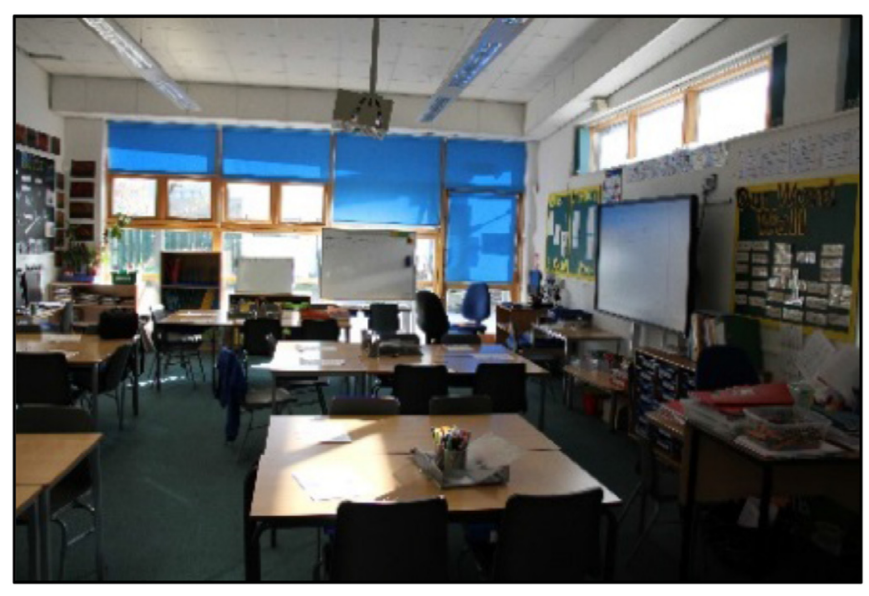

Fig. 2. Classroom providing low opportunities for children's window operation.

small openings at high windowsill $(1.7 \mathrm{~m})$ located at the end of the classroom.

Due to the potential impact of blinds on resisting airflows $[50,66]$, the study considers the impact of blinds on obstructing window open area. This study obtained its ethic approval before the start of the project and all ethical considerations were followed during field study, including getting consent from heads, teachers and children.

\subsubsection{Occupants}

To study adaptive behaviours of primary school children, it is important to select an age group that has a clear perception of environmental conditions. In this study, 9-11 years old children were targeted for two main reasons. 1) Primary school children in their late middle childhood (9-11 years old) compared to their peers in early middle childhood (6-8 years old) are more likely to operate controls because of their height. Children's heights were derived from UK-World Health Organisation (WHO) growth charts; average height of 9-11 years old children are reported to be 133, 138 and $144 \mathrm{~cm}$, respectively [67]. Another study suggests that older children have more freedom to operate controls whereas the younger children are supervised more strictly inside the classrooms [68]. 2) Children in their late middle childhood (9-11 years old) compared to their peers can provide more valid responses to a structured questionnaire. They also have more developed language and literacy skills [69], cognitive abilities [70] and attention span [71]. Children at this age compared to their peers think more productively and evaluate facts better [71], which can increase data quality and consistency of findings [69].

\subsection{Environmental variables and adaptive behaviours}

Personal and environmental adaptive behaviours and simultaneous environmental measurements were conducted in selected classrooms.

\subsubsection{Environmental measurements}

Environmental variables affecting thermal environment and adaptive behaviours were recorded at 5-min intervals by multifunctional SWEMA equipment [72] and standalone data loggers [73]. Table 3 shows details of the environmental equipment with their range, resolution and accuracy. SWEMA equipment, designed to comply with ISO 7726 [74] and ISO $7730[72,75]$ standards, collects data from three sensors: 'air velocity and temperature', 'humidity and temperature' and 'radiant temperature' (globe thermometer $\varnothing 150 \mathrm{~mm}$ ). The location of the sensors varies in each classroom with regards to children's health and safety and the setup criteria. A measurement station was located at a height of $1.1 \mathrm{~m}$ as recommended by ISO 7726 [74], away from heat sources (e.g. projectors), main airflows (e.g. windows) and sun patches. Equipment was placed within vicinity of children's desks without impairing their safety, seating arrangement or visual comfort. For instruments' acclimatization to the classrooms' thermal environment [18], they were usually set up before children's arrival in the morning. To record state of windows and doors, time-lapse cameras were installed inside the classrooms alongside visual observations by the lead author.

\subsubsection{Thermal perception and adaptive behaviours}

To record thermal perception and related adaptive behaviours, a reliable and valid method which was validated by the authors [76] was employed. In this method, children were surveyed on personal adaptive behaviours including fanning, drinking and clothing through a self-reported questionnaire, Table 4 . Children and teachers' interactions with windows and doors were recorded using the observation form, Table 4. Children were surveyed on their thermal sensation and preference by 5-point rating scales as (Cold, Cool, OK, Warm, Hot) and (Warmer, A little warmer, As it is, A little cooler and Cooler).

To record all adaptive behaviours during sessions, children were asked to fill out the paper-based questionnaire at the end of sessions. Children maintained a stable activity level at least $30 \mathrm{~min}$ before filling out questionnaire, as suggested by Goto et al., 2002 [77]. In total, 805 children were observed, and 1390 questionnaires were collected during field studies.

Schools in UK require pupils to wear uniforms which can restrict available clothing choices [78], therefore, children have a specific range of school uniform options [31]. However, children in this study could wear a seasonal variant of the uniform if they wished to. Children's clothing uniform was surveyed (Table 4), however, Top part of clothing uniform is not questioned as 'shortsleeve shirt/blouse' and 'light-weight long-sleeve shirt/blouse' have similar Clo values [75]. Clothing values in Table 5 were estimated according to ISO 7730 [75] by considering children's fixed layers (i.e. worn for the whole day) and adjustable layers (i.e. Jumper/cardigan) [76]. All combinations include underwear, and when jumper/cardigan is worn, 0.25 is added to Clo value [31]. Table 5 shows uniform combinations in studied classrooms with a total of eight different Clo values. 
Table 2

An overview of architectural features of schools and classrooms

\begin{tabular}{|c|c|c|c|c|c|c|c|c|c|c|c|c|}
\hline \multicolumn{3}{|c|}{ General information } & \multicolumn{3}{|c|}{ Classrooms' characteristics } & \multicolumn{6}{|c|}{ Controls' configurations } & \multirow{2}{*}{$\begin{array}{l}\text { Overall } \\
\mathrm{Op}^{3} \text { for } \mathrm{W} \mathrm{OP}^{4}\end{array}$} \\
\hline $\begin{array}{l}\text { Schools' Plan } \\
\text { form }\end{array}$ & Mode and season & No. & Floor & $\begin{array}{l}\text { Classroom } \\
\text { Orientation }\end{array}$ & $\begin{array}{l}\text { Class } \\
\text { Area }\left(\mathrm{m}^{2}\right)\end{array}$ & $\begin{array}{l}\text { Window } \\
\text { Area }\left(\mathrm{m}^{2}\right)\end{array}$ & No. $W^{1}$ & $\begin{array}{l}\text { Window } \\
\text { Operation }\end{array}$ & Type of Window & $\begin{array}{l}\text { Min height } \\
\text { Windowsill }\end{array}$ & $\mathrm{Ex}^{2}$ door & \\
\hline \multirow{5}{*}{ 1. Linear } & \multirow{5}{*}{$\begin{array}{l}\text { Non-heating seasons, } \\
\text { Summer }(07 / 17)\end{array}$} & 1.1 & First & $\mathrm{NE}$ & 60 & 8 & 8 & Manually & Top-hung & 1 & No & $\mathrm{H}$ \\
\hline & & 1.2 & First & SW & 60 & 8 & 8 & Manually & outward & 1 & No & $\mathrm{H}$ \\
\hline & & 1.3 & First & SW & 60 & 8 & 8 & Manually & openings at two & 1 & No & $\mathrm{H}$ \\
\hline & & 1.4 & First & SW & 60 & 8 & 8 & Manually & levels & 1 & No & $\mathrm{H}$ \\
\hline & & 1.5 & First & $\mathrm{NE}$ & 60 & 8 & 8 & Manually & & 1 & No & $\mathrm{H}$ \\
\hline \multirow[t]{4}{*}{ 2. L-shaped } & \multirow{4}{*}{$\begin{array}{l}\text { Non-heating, } \\
\text { Autumn (09/17) }\end{array}$} & 2.6 & First & NW & 60 & 8 & 8 & Manually & Top-hung & 1 & No & $\mathrm{H}$ \\
\hline & & 2.7 & First & $\mathrm{SE}$ & 60 & 8 & 8 & Manually & outward & 1 & No & $\mathrm{H}$ \\
\hline & & 2.8 & First & SE & 60 & 8 & 8 & Manually & openings at two & 1 & No & $\mathrm{H}$ \\
\hline & & 2.9 & First & NW & 60 & 8 & 8 & Manually & levels & 1 & No & $\mathrm{H}$ \\
\hline \multirow[t]{3}{*}{ 3. Triangle } & \multirow{3}{*}{$\begin{array}{l}\text { Heating, Autumn } \\
(10 / 17)\end{array}$} & 3.10 & Ground & $S \& W$ & 65 & 2 & 5 & Manually & Top-hung & 1.7 & Yes & $\mathrm{L}$ \\
\hline & & 3.11 & Ground & $S \& W$ & 70 & 2.2 & 6 & Manually & outward & 1.6 & No & $\mathrm{L}$ \\
\hline & & 3.12 & First & NW & 60 & 2.5 & 5 & With a handle & & 2.6 & No & $\mathrm{L}$ \\
\hline & Heating, Autumn & 4.13 & Ground & W & 50 & 0.5 & 2 & Manually & Top-hung & 1.8 & Yes & $\mathrm{L}$ \\
\hline \multirow{2}{*}{ a courtyard } & \multirow{2}{*}{ (11/17) } & 4.14 & Ground & w & 60 & 0.5 & 2 & Manually & outward & 1.8 & Yes & $\mathrm{L}$ \\
\hline & & 4.15 & Ground & No W & 50 & 0 & 0 & No window & - & - & No & $\mathrm{L}$ \\
\hline \multirow[t]{5}{*}{ 5. T-shaped } & \multirow{5}{*}{$\begin{array}{l}\text { Heating Mode, } \\
\text { Winter }(01 / 18)\end{array}$} & 5.16 & First & SW, SE & 55 & 5.7 & 8 & Manually & Top-hung & 0.5 & No & $\mathrm{H}$ \\
\hline & & 5.17 & First & SW & 55 & 5.7 & 8 & Manually & outward & 0.5 & No & $\mathrm{H}$ \\
\hline & & 5.18 & First & SW \& NW & 55 & 5.7 & 8 & Manually & openings at two & 0.5 & No & $\mathrm{H}$ \\
\hline & & 5.19 & Ground & SW & 55 & 5.7 & 8 & Manually & levels & 0.5 & Yes & $\mathrm{H}$ \\
\hline & & 5.20 & Ground & SW \& NW & 55 & 5.7 & 8 & Manually & & 0.5 & Yes & $\mathrm{H}$ \\
\hline \multirow[t]{5}{*}{ 6. Linear } & \multirow{5}{*}{$\begin{array}{l}\text { Heating Mode, } \\
\text { Winter }(02 / 18)\end{array}$} & 6.21 & First & SE & 60 & 1.8 & 4 & Remote-control & Top-hung & 2.3 & No & $\mathrm{L}$ \\
\hline & & 6.22 & First & $\mathrm{SE}$ & 60 & 1.8 & 4 & Remote-control & outward opening & 2.3 & No & $\mathrm{L}$ \\
\hline & & 6.23 & First & $\mathrm{SE}$ & 60 & 1.8 & 4 & Remote-control & & 2.3 & No & $\mathrm{L}$ \\
\hline & & 6.24 & First & $\mathrm{SE}$ & 60 & 1.8 & 4 & Remote-control & & 2.3 & No & $\mathrm{L}$ \\
\hline & & 6.25 & First & SE & 60 & 1.8 & 4 & Remote-control & & 2.3 & No & $\mathrm{L}$ \\
\hline \multirow{3}{*}{$\begin{array}{l}\text { 7. } \operatorname{Rec}^{5} \text { with } \\
\text { a courtyard }\end{array}$} & \multirow{3}{*}{$\begin{array}{l}\text { Non-heating, Spring } \\
(04 / 18)\end{array}$} & 7.26 & Ground & SE \& SW & 70 & 3.9 & 6 & With a handle & Top-hung & 2.7 & No & $\mathrm{L}$ \\
\hline & & 7.27 & Ground & SE \& SW & 55 & 3.3 & 3 & Manually & outward opening & 1.65 & Yes & $\mathrm{L}$ \\
\hline & & 7.28 & First & NE \& NW & 55 & 5.4 & 6 & Manually & & 1.6 & No & $\mathrm{L}$ \\
\hline \multirow{4}{*}{$\begin{array}{l}\text { 8. } \operatorname{Rec}^{5} \text { with } \\
2 \text { courtyards }\end{array}$} & \multirow{4}{*}{$\begin{array}{l}\text { Non-heating seasons, } \\
\text { Spring }(05 / 18)\end{array}$} & 8.29 & Ground & $\mathrm{NE}$ & 60 & 2.2 & 4 & Manually & Top-hung & 1.4 & Yes & $\mathrm{L}$ \\
\hline & & 8.30 & Ground & $\mathrm{NE}$ & 60 & 2.2 & 4 & Manually & outward opening & 1.4 & Yes & $\mathrm{L}$ \\
\hline & & 8.31 & Ground & NW & 55 & 2.2 & 4 & Manually & & 1.4 & Yes & $\mathrm{L}$ \\
\hline & & 8.32 & Ground & NW & 55 & 2.2 & 4 & Manually & & 1.4 & Yes & $\mathrm{L}$ \\
\hline
\end{tabular}

$1=$ Window, $2=$ Exterior, $3=$ Opportunities, $4=$ Operation, $5=$ Rectangular 
Table 3

Specifications of the measuring equipment.

\begin{tabular}{|c|c|c|c|c|}
\hline Probe & & Range & Resolution & Accuracy \\
\hline \multirow[t]{5}{*}{ SWEMA [72] } & Humidity and & $0-100 \%$ RH, & $0.1 \% \mathrm{RH}$ & $\pm 0.8 \% \mathrm{RH}$ at $23^{\circ} \mathrm{C}$ \\
\hline & air temperature & -40 to $+60^{\circ} \mathrm{C}$ & $0.1^{\circ} \mathrm{C}$ & $\pm 0.3^{\circ} \mathrm{C}$ at $23^{\circ} \mathrm{C}$ \\
\hline & Air velocity and & $0.05-3.0 \mathrm{~m} / \mathrm{s}$ at 15 to & $0.01 \mathrm{~m} / \mathrm{s}$ & $\pm 0.04 \mathrm{~m} / \mathrm{s}$ at 0.05 to $1.00 \mathrm{~m} / \mathrm{s}$ \\
\hline & Air temperature & $30^{\circ} \mathrm{C},+10$ to $+40^{\circ} \mathrm{C}$ & $0.1^{\circ} \mathrm{C}$ & $\pm 4 \%$ read value at 1.0 to $3.0 \mathrm{~m} / \mathrm{s}$ \\
\hline & $\begin{array}{l}\text { Radiant temperature ( } \\
\text { globe: approx. } 150 \mathrm{~mm} \text { ) }\end{array}$ & $0-+50^{\circ} \mathrm{C}$ & $0.1^{\circ} \mathrm{C}$ & $\pm 0.1^{\circ} \mathrm{C}$ \\
\hline Temperature/Humidity & Temperature & -35 to $+80^{\circ} \mathrm{C}$ & $0.1^{\circ} \mathrm{C}$ & $\pm 0.3^{\circ} \mathrm{C}$ \\
\hline Data Logger [73] & Humidity & $0-100 \%$ RH & $0.5 \% \mathrm{RH}$ & $\pm 0.2 \% \mathrm{RH}$ \\
\hline
\end{tabular}

\subsection{Calculating comfort temperature}

According to Nicol and Humphreys (2010), comfort or neutral temperature is defined as "operative temperature at which the average person is thermally neutral" [27]. To calculate comfort temperature, standards including ISO 7730 [75], ASHRAE 55 [28] and EN 15251 [79] rely on thermos-physiological [80] and adaptive $[40,81]$ models. The adaptive model acknowledges that people are in dynamic equilibrium with their environment [82] and can interact with it $[18,83]$. Both American (ASHRAE 55) [28] and European (EN 15251) [79] standards developed adaptive models for adults in naturally-ventilated buildings based on prevailing outdoor conditions $[18,40,84]$.

EN 15251 [79] adopts exponentially weighted running mean temperature $\left(T_{r m}\right)$ that considers the significance of temperatures based on their distance in the past from Eq. (1):

$T_{r m}=\frac{T_{o d-1}+\alpha T_{o d-2}+\alpha^{2} T_{o d-3}+\cdots}{1+\alpha+\alpha^{2}+\cdots}$ for $0<\alpha<1$

where constant $\alpha$ is $0.8, T_{o d-1}$ is the daily mean outdoor temperature for the previous day; $\mathrm{To}_{\mathrm{d}-1}$ is the daily mean outdoor temperature for the day before that and so on [18]. Comfort temperature according to main studies on adaptive models $[18,83]$ and CIBSE, 2006 [85] is calculated from Eq. (2) during non-heating seasons and Eq. (3) during heating seasons.

$T_{C E N}=0.33 T_{r m}+18.8^{\circ} \mathrm{C}, T_{r m}>10$

$T_{\text {CEN }}=0.09 T_{r m}+22.6^{\circ} \mathrm{C}, T_{r m} \leq 10$

EN 15251 considers different building categories; Category I with high expectations for sensitive and vulnerable occupants, Category II for normal expectations in new or renovated buildings, Category III for moderate levels of expectation in existing buildings [79]. Eqs. (4)-(6) show the calculation of comfort temperatures in Building Categories I, II and III.

$$
\begin{aligned}
& \text { Category I buildings : } T_{C E N}=0.33 T_{r m}+18.8^{\circ} \mathrm{C} \pm 2, T_{r m}>10 \\
& \text { Category II buildings : } T_{C E N}=0.33 T_{r m}+18.8^{\circ} \mathrm{C} \pm 3, T_{r m}>10 \\
& \text { CategoryIIIbuildings : } T_{C E N}=0.33 T_{r m}+18.8^{\circ} \mathrm{C} \pm 4, T_{r m}>10
\end{aligned}
$$

\subsection{Overview of the recorded data}

Outdoor $\left(\mathrm{T}_{\text {out }}\right)$ and indoor operative temperature $\left(\mathrm{T}_{\mathrm{op}}\right)$ at the time of filling out questionnaires, day's running mean temperature $\left(\mathrm{T}_{\mathrm{rm}}\right)$, comfort temperature predicted by EN 15251 [79] ( $\left.\mathrm{T}_{\mathbf{C}(\mathrm{CEN})}\right)$, temperature offset form comfort temperature ' $T_{\text {diff }}=T_{\text {op }}-T_{C}($ CEN)', mean Thermal Sensation votes (TSVs) and mean clothing values (Clo) are presented in Table 6 to characterize classrooms' thermal environment and children's thermal perception.

Fig. 3 shows the percent of children in each category of TSVs and thermal preference votes (TPVs). Around 15\% of the children during non-heating seasons and $14 \%$ during heating seasons are overheated (i.e. proportion of children who feel warm or hot and prefer a cooler classroom).
Fig. 4 shows the percent of children in each category of Clothing value. During heating seasons, $77 \%$ of children's clothing values are in Cat D. During non-heating seasons, clothing values are more diverse, $32 \%$ in Cat A, 30\% in Cat B, $12 \%$ in Cat C, and $26 \%$ in Cat D, Fig. 4.

\section{Results}

\subsection{Children's comfort temperature $\left(T_{C(\text { children })}\right)$ vs en comfort temperature $\left(T_{C(C E N)}\right)$}

To investigate children's adaptive behaviour as an action to reach thermal comfort, there is a need to discover children's thermal comfort ( $\mathrm{T}_{\mathbf{C} \text { (children) }}$ ). The Equations by EN 15251 [79] for optimum comfort temperature were developed based on data collected from office workers in the SCATs project [18]. Therefore, predicted comfort temperature estimates adults' comfort temperature $\left(\mathrm{T}_{\left.\mathbf{C}_{(\mathrm{CEN})}\right)}\right.$ more reliably than that for adults. Evidence shows that outdoor climatic conditions affect thermal adaptation to indoor conditions significantly [79]. Therefore, the distance between indoor operative temperature $\left(\mathrm{T}_{\mathrm{op}}\right)$ and the day's comfort temperature by EN 15251 ( $\left.\mathrm{T}_{\mathbf{C}(\mathrm{CEN})}\right)$ [79] $\left(\mathrm{T}_{\mathrm{diff}}=\mathrm{T}_{\mathrm{op}}-\mathrm{T}_{\mathbf{C}(\mathrm{CEN})}\right)$ is considered as the criteria for suggesting children's comfort temperature

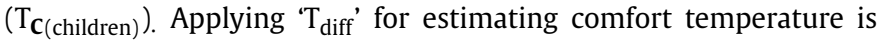
supported in similar studies exploring children's comfort temperature at schools $[44,86]$. Children's mean TSVs and TPVs for each survey were compared with ' $\mathrm{T}_{\text {diff' }}$ ' to provide a more detailed presentation of results. The method to calculate comfort temperatures is presented in the following three steps:

Step 1) The difference between $T_{o p}$ and the day's comfort temperature predicted by EN 15251 adaptive model [79] $\left(\mathrm{T}_{\mathrm{diff}}=\mathrm{T}_{\mathrm{op}}\right.$ $\mathrm{T}_{\mathbf{C} \text { (CEN) }}$ ) was calculated. $\mathrm{T}_{\text {diff }}$ values greater than 0 account for temperatures higher than comfort temperature predicted by EN 15251 and $\mathrm{T}_{\text {diff }}$ values lower than 0 account for temperatures lower than comfort temperature by EN 15251. Step 2) The proportion of children with Warm Sensation (i.e. $0<\mathrm{TSV}$, the one who voted Warm or Hot), Cool Sensation (i.e. TSV $<0$, the ones who voted Cool or Cold) and Neutral sensation (i.e. $\mathrm{TSV}=0$, the ones who voted $\mathrm{OK}$ ) was calculated for each classroom and plotted against corresponding $\mathrm{T}_{\text {diff, }}$, Figs. 5and 6. The intersection point of 'Warm sensation' and 'Cool sensation' graphs is the point at which proportion of children feeling warm and feeling cool is similar. Indeed, it introduces the point at which equilibrium is reached. To suggest this point as $\mathrm{T}_{\mathrm{C}(\mathrm{CHILDREN})}$, the proportion of children feeling 'OK' should approximately be maximum at this point. Step 3). Similarly, the proportion of children with Warmer preference (i.e. $0<\mathrm{TPV}$, the ones who preferred a bit warmer or warmer classroom), Cooler preference (i.e. $0>\mathrm{TPV}$, the ones who preferred a bit cooler or cooler classroom) and 'As it is' preference was calculated and plotted against the related $\mathrm{T}_{\text {diff, }}$, Figs. 5and 6. Similarly, the intersection point of 'Warmer preference' and 'Cooler preference' graphs suggests the 'preferred temperature'. At this point, the proportion of children preferring the classroom 'as it is' should approximately be maximum. This approach is supported in similar stud- 
Table 4

Questions on thermal perception and adaptive behaviours from questionnaire and observation Forms [76]

\begin{tabular}{|c|c|c|c|c|c|c|c|}
\hline \multicolumn{2}{|l|}{ Variables } & \multirow{2}{*}{$\begin{array}{l}\text { Questions } \\
\text { How do you feel now? }\end{array}$} & \multicolumn{5}{|l|}{ Scales and coding } \\
\hline Thermal Comfort and & (Method: & & Cold $(-2) \square$ & Cool $(-1) \square$ & $\mathrm{OK}(0) \square$ & Warm $(+1) \square$ & Hot $(+2) \square$ \\
\hline \multirow[t]{5}{*}{ Personal Behaviours } & \multirow[t]{5}{*}{ Questionnaire) } & $\begin{array}{l}\text { How would you like the } \\
\text { classroom to be now? }\end{array}$ & Warmer $(+2) \square$ & $\begin{array}{l}\text { A little warmer } \\
(+1) \square\end{array}$ & As it is (0) $\square$ & $\begin{array}{l}\text { A little cooler }(-1) \\
\square\end{array}$ & Cooler $(-2) \square$ \\
\hline & & I am wearing ... now. & $\begin{array}{l}\text { A skirt or dress } \\
\text { with socks }(0.39 \\
\text { Clo value) } \square\end{array}$ & $\begin{array}{l}\text { Trousers } \\
(0.49 \text { Clo value }) \square\end{array}$ & \multicolumn{2}{|c|}{$\begin{array}{l}\text { A skirt or dress with tights } \\
\text { ( } 0.47 \text { Clo value) } \square\end{array}$} & $\begin{array}{l}\text { Shorts } \\
\text { (0.3 Clo value) } \square\end{array}$ \\
\hline & & $\begin{array}{l}\text { Are you wearing a jumper } \\
\text { or cardigan now? }\end{array}$ & Yes $\square$ & \multicolumn{2}{|c|}{ No, I took it off in the morning $\square$} & \multicolumn{2}{|c|}{ I don't have a jumper or cardigan today $\square$} \\
\hline & & $\begin{array}{l}\text { Did you fan yourself this } \\
\text { morning? }\end{array}$ & \multicolumn{2}{|l|}{ Yes $\square$} & \multicolumn{3}{|l|}{ No $\square$} \\
\hline & & $\begin{array}{l}\text { Did you have any drink } \\
\text { this morning? }\end{array}$ & $\begin{array}{l}\text { Yes, I had a cold } \\
\text { drink } \\
\square\end{array}$ & $\begin{array}{l}\text { Yes, I had a warm } \\
\text { drink } \square\end{array}$ & \multicolumn{2}{|c|}{$\begin{array}{l}\text { Yes, I had both cold and warm drink } \\
\square\end{array}$} & $\begin{array}{l}\text { No, I did not have } \\
\text { any drink } \square\end{array}$ \\
\hline \multirow{12}{*}{ Behaviours } & (Method: & Type of controls & \multirow{10}{*}{\multicolumn{2}{|c|}{$\begin{array}{l}\text { State of controls } \\
\text { Number/percent of fully open large windows } \\
\left(>1 \mathrm{~m}^{2}\right): \\
\text { Number/percent of slightly open large } \\
\text { windows }\left(>1 \mathrm{~m}^{2}\right) \text { : } \\
\text { Number/percent of fully open small windows } \\
\left(<1 \mathrm{~m}^{2}\right): \\
\text { Number/percent of slightly open small } \\
\text { windows }(<1 \mathrm{~m} 2) \text { : } \\
\text { Total No. of window adjustment? ... } \\
\text { Percent of open windows covered by blinds? ... } \\
\text { Sate of internal door ( } \square \text { Open, } \square \text { Closed) }\end{array}$}} & \multirow{5}{*}{\multicolumn{2}{|c|}{$\begin{array}{l}\text { Reason for adjustment? } \\
\square \text { Temperature, } \square \text { wind, } \square \text { noise } \\
\square \text { rain or snow, } \square \text { upon arrival } \\
\square \text { on departure, } \square \text { turning the air conditioner } \\
\text { or fan on }\end{array}$}} & \multirow{10}{*}{$\begin{array}{l}\text { Adjustment by? } \\
\square \text { Teacher } \\
\square \text { Teacher assistant } \\
\square \text { Caretaker } \\
\square \text { Student on } \\
\text { his/her will } \\
\square \text { Student on } \\
\text { teacher's request } \\
\square \text { Teacher on } \\
\text { student's request }\end{array}$} \\
\hline & \multirow{11}{*}{ Observation) } & & & & & & \\
\hline & & Windows & & & & & \\
\hline & & & & & & & \\
\hline & & & & & & & \\
\hline & & & & & & & \\
\hline & & & & & & & \\
\hline & & & & & & & \\
\hline & & & & & & & \\
\hline & & & & & \multirow{3}{*}{\multicolumn{2}{|c|}{$\begin{array}{l}\square \text { Noise, } \square \text { ventilation, } \square \text { temperature, } \\
\square \text { occupancy patterns }\end{array}$}} & \\
\hline & & Doors & \multicolumn{2}{|c|}{ Connecting door ( $\square$ Open, $\square$ Closed) } & & & \\
\hline & & & \multicolumn{2}{|c|}{ State of exterior door ( $\square$ Open, $\square$ Closed) } & & & \\
\hline
\end{tabular}


Table 5

School uniform clothing combinations.

\begin{tabular}{llllllll}
\hline Cat & No. & School uniform clothing combinations & Clo & Cat & No. & Clothing combinations & Clo \\
\hline A & 1 & Shirt/blouse, shorts, socks, shoes & 0.30 & C & $\mathbf{2}$ & No. 1+ jumper/cardigan & 0.55 \\
& 3 & Shirt/blouse, light skirt, socks, shoes & 0.39 & & $\mathbf{4}$ & No. 3+ jumper/cardigan & 0.64 \\
B & 5 & Shirt/blouse, light skirt, tights, shoes & 0.47 & D & $\mathbf{6}$ & No. 5+ jumper/cardigan & 0.72 \\
& 7 & Shirt/blouse, normal trousers, socks, shoes & 0.49 & & $\mathbf{8}$ & No. 7+ jumper/cardigan & 0.74 \\
\hline
\end{tabular}

Table 6

Overview of recorded data in each classroom.

\begin{tabular}{|c|c|c|c|c|c|c|c|}
\hline Classroom no & $\mathrm{T}_{\mathrm{op}}$ & $\mathrm{T}_{\text {out }}$ & $\mathrm{T}_{\mathrm{rm}}$ & $\mathrm{T}_{\mathrm{C}(\mathbf{C E N})}$ & $\mathrm{T}_{\text {diff }}$ & TSV & Clo Value \\
\hline 1.1 & 25.5 & 22.8 & 15.4 & 23.9 & 1.6 & 0.1 & 0.46 \\
\hline 1.2 & 27.6 & 24.3 & 16.5 & 24.2 & 3.4 & 1.0 & 0.38 \\
\hline 1.3 & 26.5 & 20.7 & 17.7 & 24.7 & 1.8 & 0.5 & 0.36 \\
\hline 1.4 & 26.4 & 16.6 & 18.3 & 24.8 & 1.6 & 0.4 & 0.47 \\
\hline 1.5 & 25.4 & 17.4 & 18.2 & 24.8 & 0.6 & 0.5 & 0.38 \\
\hline 2.6 & 23.9 & 14.1 & 9.3 & 23.4 & 0.5 & -0.1 & 0.55 \\
\hline 2.7 & 24.4 & 15.6 & 12.2 & 22.8 & 1.6 & 0.7 & 0.60 \\
\hline 2.8 & 25.2 & 17.4 & 12.7 & 23.0 & 2.2 & 0.6 & 0.58 \\
\hline 2.9 & 25.3 & 17.5 & 13.1 & 23.1 & 2.2 & 0.6 & 0.56 \\
\hline 3.10 & 22.5 & 9.5 & 8.7 & 23.4 & -0.9 & -0.2 & 0.64 \\
\hline 3.11 & 24.0 & 12.7 & 7.3 & 23.3 & 0.7 & 0.5 & 0.68 \\
\hline 3.12 & 21.8 & 11.9 & 6.8 & 23.2 & -1.4 & 0.3 & 0.69 \\
\hline 4.13 & 24.7 & 11.6 & 6.0 & 23.1 & 1.6 & 0.6 & 0.64 \\
\hline 4.14 & 23.5 & 14.2 & 7.2 & 23.2 & 0.3 & 0.1 & 0.69 \\
\hline 4.15 & 24.1 & 6.4 & 8.0 & 23.3 & 0.8 & 0.4 & 0.65 \\
\hline 5.16 & 22.3 & 8.1 & 5.9 & 23.1 & -0.8 & 0.2 & 0.72 \\
\hline 5.17 & 21.2 & 5.9 & 6.3 & 23.2 & -2 & -0.1 & 0.71 \\
\hline 5.18 & 19.5 & 4.6 & 5.7 & 23.1 & -3.6 & 0.1 & 0.71 \\
\hline 5.19 & 23.4 & 5.7 & 5.7 & 23.1 & 0.3 & 0.4 & 0.70 \\
\hline 5.20 & 22.8 & 6.7 & 5.5 & 23.1 & -0.3 & 0.8 & 0.69 \\
\hline 6.21 & 25.0 & 5.1 & 2.4 & 22.8 & 2.2 & 0.6 & 0.69 \\
\hline 6.22 & 22.8 & 4.2 & 2.3 & 22.8 & 0 & 0.5 & 0.67 \\
\hline 6.23 & 21.8 & 7.8 & 2.3 & 22.8 & -1 & 0.4 & 0.63 \\
\hline 6.24 & 20.8 & 7.1 & 3.0 & 22.9 & -2.1 & 0.2 & 0.69 \\
\hline 7.26 & 22.9 & 13.8 & 7.6 & 23.3 & -0.4 & 0.6 & 0.68 \\
\hline 7.27 & 23.4 & 20.4 & 8.5 & 23.4 & 0 & 0.3 & 0.49 \\
\hline 7.28 & 22.5 & 24.5 & 10.2 & 22.2 & 0.3 & 0.6 & 0.62 \\
\hline 8.29 & 23.5 & 18.7 & 11.7 & 22.7 & 0.8 & 0.4 & 0.47 \\
\hline 8.30 & 19.6 & 16.5 & 11.6 & 22.6 & -3 & -0.2 & 0.55 \\
\hline 8.31 & 22.8 & 11.5 & 12.0 & 22.8 & 0 & -0.1 & 0.65 \\
\hline 8.32 & 21.9 & 14.3 & 12.0 & 22.8 & -0.9 & 0.2 & 0.63 \\
\hline
\end{tabular}

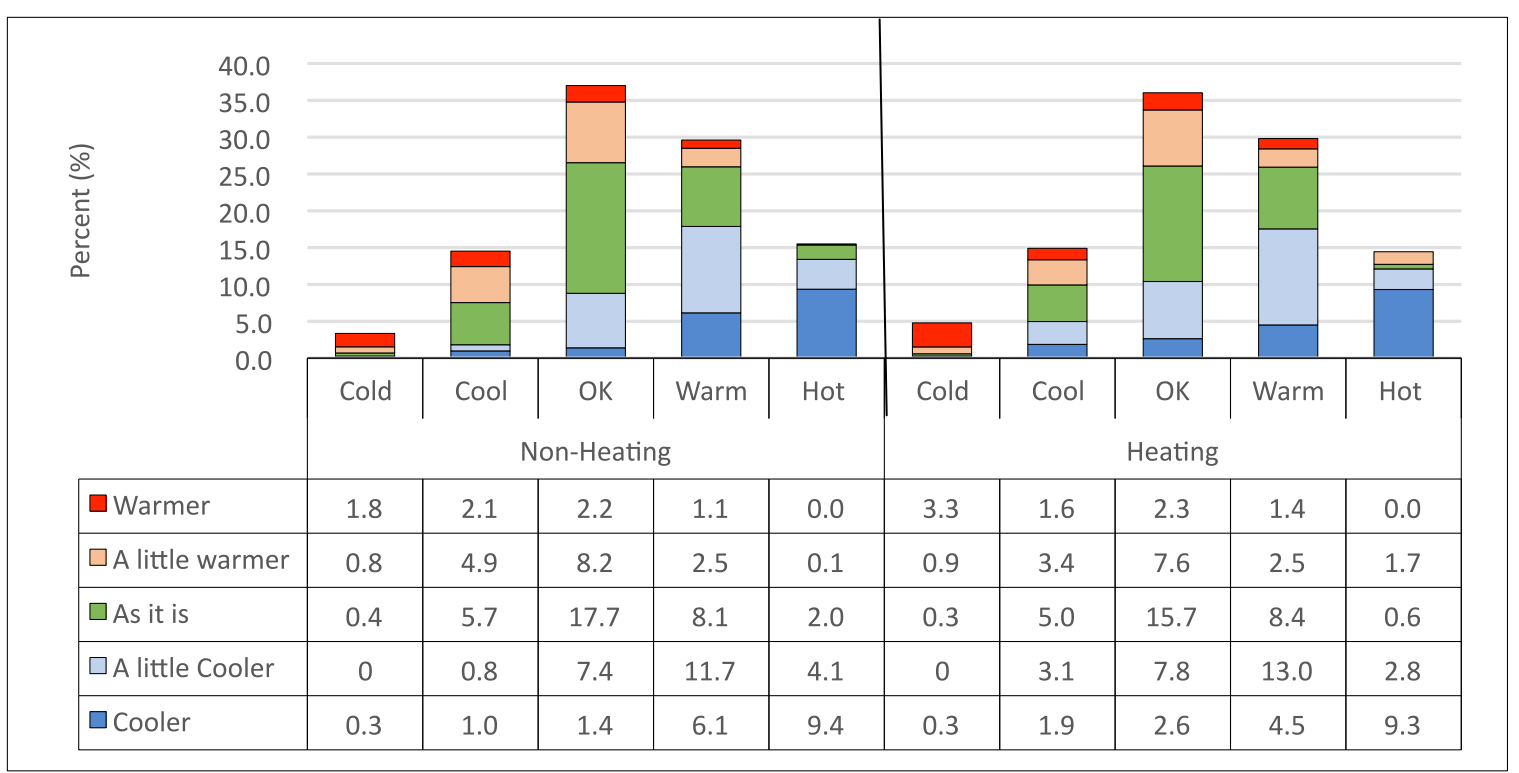

Fig. 3. Percent of children in each category of TSV and TPV. 


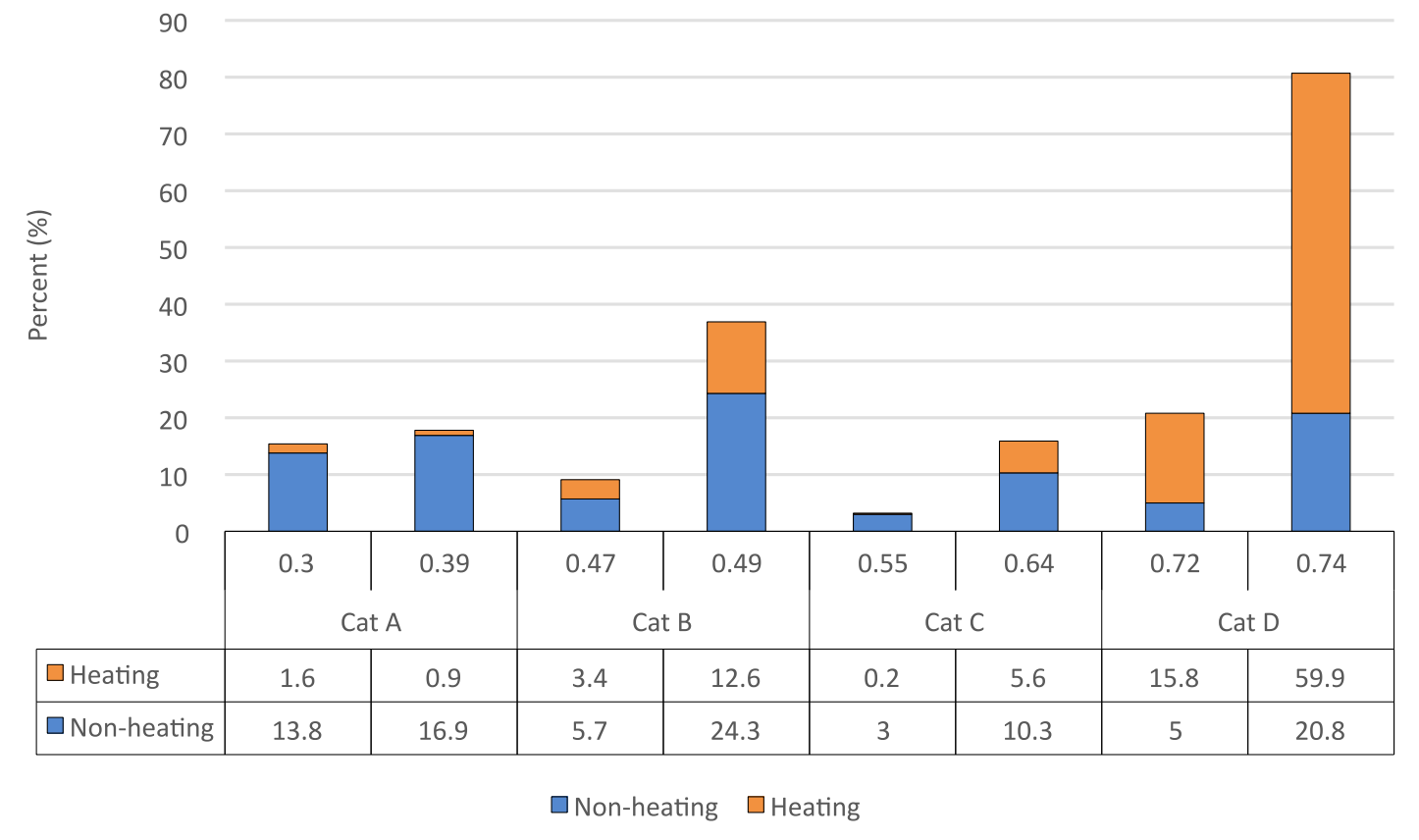

Fig. 4. Distribution (\%) of children's clothing values.

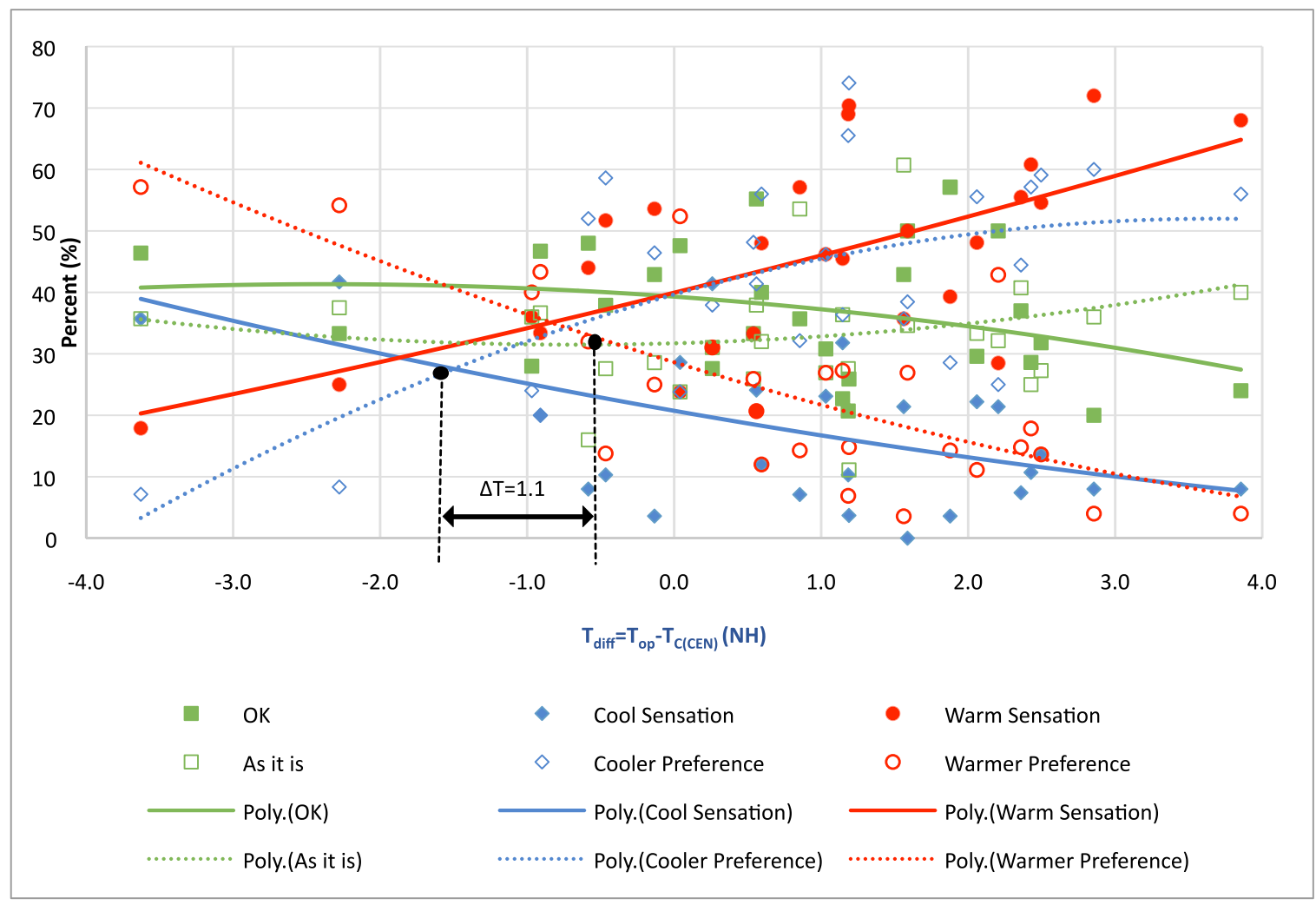

Fig. 5. Proportion of children in different groups of sensation and preference in relation to $T_{\text {diff }}(\mathrm{NH})$.

ies $[17,34,86]$ that show intersection point of 'Want warmer' and 'Want cooler' probit models as the preferred temperature.

Non-heating seasons: As it can be seen in Fig. 5, the intersection point of warm sensation and cool sensation curves is at $\mathrm{T}_{\text {diff }}=-1.9$ during non-heating seasons, $1.9 \mathrm{~K}$ cooler than $\mathrm{T}_{\mathbf{C}(\mathrm{CEN})}$. It represents the point at which $30 \%$ of the children have Cool sen- sation and 30\% have Warm sensation. The proportion of children with neutral sensation (the rest $40 \%$ ) is at its peak at this point, Fig. 5. Similarly, the intersection point of warmer and cooler preference curves is at $\mathrm{T}_{\text {diff }}=-0.8$ where $34 \%$ of children prefer cooler, $34 \%$ prefer warmer and 32\% prefer 'As it is', Fig. 5. As shown in Fig. 5, there is a $1.1 \mathrm{~K}$ difference between children's comfort and 


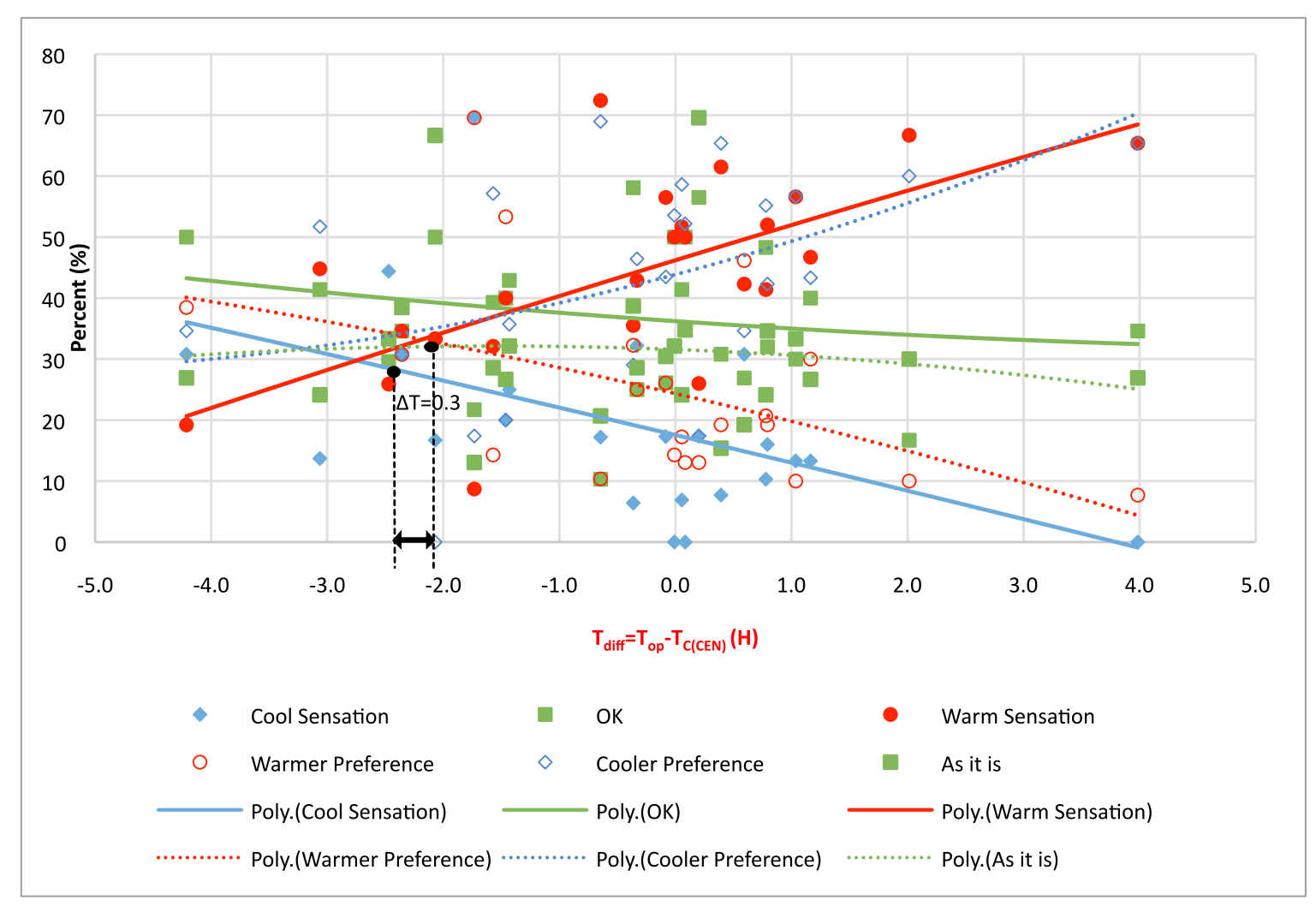

Fig. 6. Proportion of children in different groups of sensation and preference in relation to $T_{\text {diff }}(H)$.

preferred temperature. However, this difference is still within $4 \mathrm{~K}$ distance between upper and lower margin of comfort band by EN 15251 for Category I buildings $\left(\mathrm{T}_{\mathrm{C}(\mathrm{CEN})}=0.33 \mathrm{~T}_{\mathrm{rm}}+18.8^{\circ} \mathrm{C} \pm 2\right)$. $\mathrm{T}_{\mathbf{C} \text { (children) }}$ suggested in this study which happens at $\mathrm{T}_{\text {diff }}=-1.9$ is close to the lower margin of the comfort band predicted by EN $15251\left(\mathrm{~T}_{\text {diff }}=-2\right)$. Therefore, comfort temperature by EN 15251 $\left(\mathrm{T}_{\mathbf{C}(\mathrm{CEN})}\right)$ overestimates children's comfort temperature ( $\left.\mathrm{T}_{\mathbf{C} \text { (children) }}\right)$ by $1.9 \mathrm{~K}$ during non-heating seasons. At comfort temperature by EN $15251\left(T_{\text {diff }}=0\right)$, the percentage of children who feel warm increases to $40 \%$ and the percentage of children who feel OK starts to decline (Fig. 5). At upper limit of comfort band predicted by EN 15251 for Category I buildings $\left(\mathrm{T}_{\mathrm{diff}}=+2\right)$, more than $50 \%$ of children feel warm or hot and prefer a cooler classroom, Fig. 5.

Heating seasons: As can be seen in Fig. 6, the intersection point of warm and cool sensation curves is at $\mathrm{T}_{\text {diff }}=-2.8$ during heating

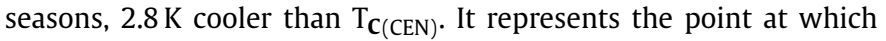
$30 \%$ of the children have Cool sensation, $30 \%$ have Warm sensation and the rest $40 \%$ have neutral sensation. At this point, the proportion of children having neutral sensation is approximately at its maximum. The intersection point of warmer and cooler preference curves is at $\mathrm{T}_{\text {diff }}=-2.4$ where $34 \%$ of children prefer cooler, $34 \%$ prefer warmer and $32 \%$ prefer 'As it is', Fig. 6. At comfort temperature predicted by EN 15251 ( $\mathrm{T}_{\text {diff }}=0$ ), the proportion of children who feel 'warm or hot' increases to $47 \%$ and the proportion of children who feel ' $O K$ ' declines to $35 \%$. The results confirm that comfort temperature predicted by EN 15251 ( $\mathrm{T}_{\mathrm{C}(\mathrm{CEN})}$ ) overestimates children's comfort temperature $\left(\mathrm{T}_{\mathbf{C} \text { (children) }}\right)$ by $2.8 \mathrm{~K}$ during heating seasons.

When $T_{\text {op }}$ equals to $T_{\mathbf{C}(C E N)}\left(T_{\text {diff }}=0\right)$, the proportion of children who have warm sensation is higher during heating seasons (47\%) than during non-heating seasons (40\%). At $\mathrm{T}_{\text {diff }}=0$, children are $12 \%$ and $20 \%$ more likely to prefer a cooler classroom than a warmer classroom during non-heating and heating seasons, respectively, Figs. 5 and 6.

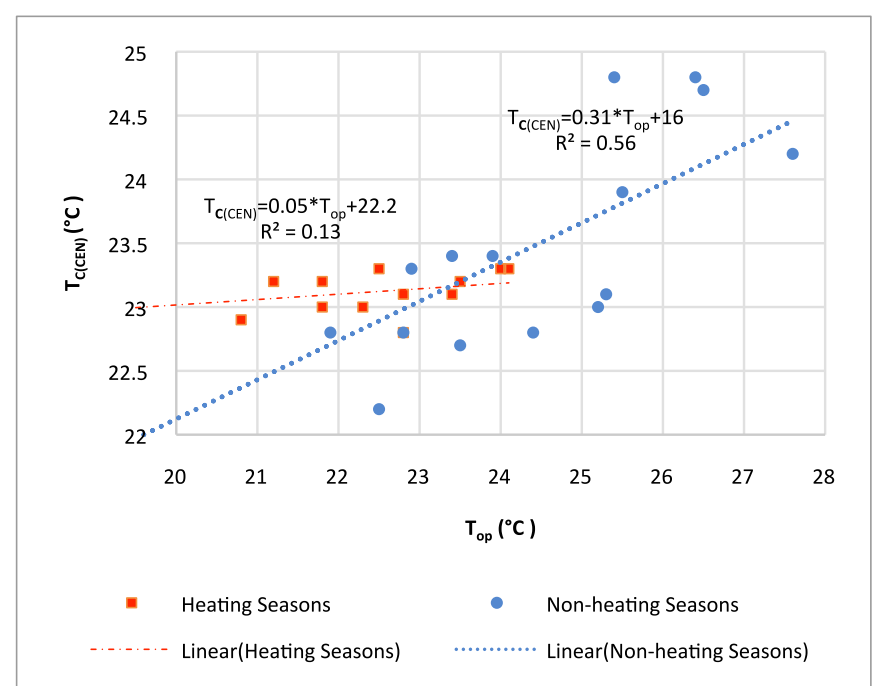

Fig. 7. $\mathrm{T}_{\mathrm{op}}$ against $\mathrm{T}_{\mathbf{C}_{(\mathrm{CEN})}}$ during non-heating and heating seasons.

EN Comfort Temperature vs Operative Temperature: To estimate values for $\mathrm{T}_{\mathbf{C} \text { (children) }}$ and $\mathrm{T}_{\mathbf{C} \text { (CEN) }}$ during both seasons, operative temperatures $\left(\mathrm{T}_{\mathrm{Op}}\right)$ are plotted against $\mathrm{T}_{\mathbf{C}(\mathrm{CEN})}$ in Fig. 7. Values for $\mathrm{T}_{\mathbf{C} \text { (children) }}$ and $\mathrm{T}_{\mathbf{C} \text { (CEN) }}$ were estimated using equation of $" \mathrm{~T}_{\text {diff }}=\mathrm{T}_{\mathrm{op}}-\mathrm{T}_{\mathbf{C}(\mathrm{CEN})}$ " in Figs. 5 and 6 and equations in Fig. 7. Based on these equations, $\mathrm{T}_{\mathbf{C} \text { (children) during non-heating seasons which }}$ is at $\mathrm{T}_{\text {diff }}=-1.9$ corresponds to $\mathrm{T}_{\mathrm{op}}$ of $20.7^{\circ} \mathrm{C}$ and $\mathrm{T}_{\mathbf{C} \text { (children) }}$ during heating seasons which is at $\mathrm{T}_{\text {diff }}=-2.8$ corresponds to $\mathrm{T}_{\mathrm{op}}$ of $20.2^{\circ} \mathrm{C}$. $\mathrm{T}_{\mathbf{C} \text { (CEN) }}$ which is at $\mathrm{T}_{\text {diff }}=0$ corresponds to $\mathrm{T}_{\mathrm{op}}$ of $23.2^{\circ} \mathrm{C}$ during non-heating seasons and $23.4^{\circ} \mathrm{C}$ during heating seasons.

Validation: To validate derived values of $\mathrm{T}_{\mathbf{C} \text { (children) }}$ from Figs. 5 to 7, the mean TSVs and TVPs are plotted against $\mathrm{T}_{\text {op }}$ using lin- 


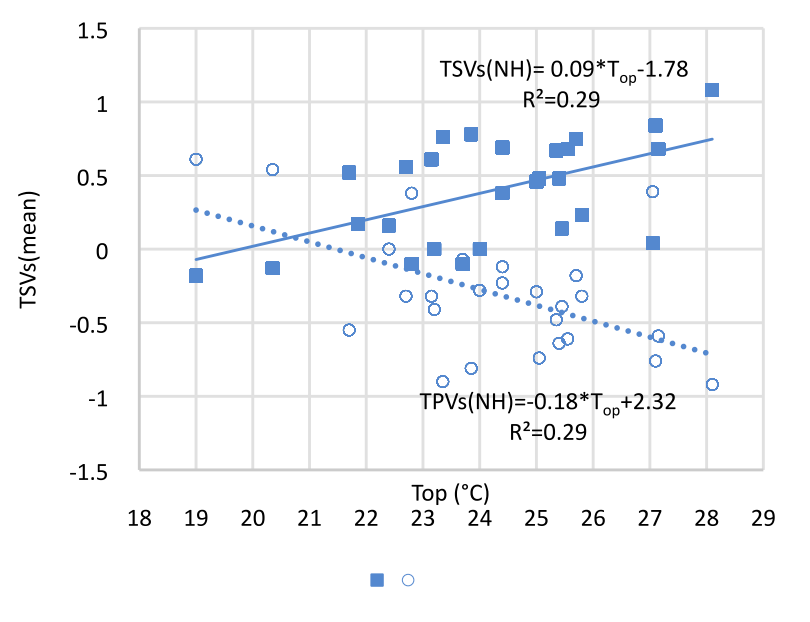

Fig. 8. Mean TSVs and TPVs against $\mathrm{T}_{\mathrm{op}}$ during non-heating seasons.

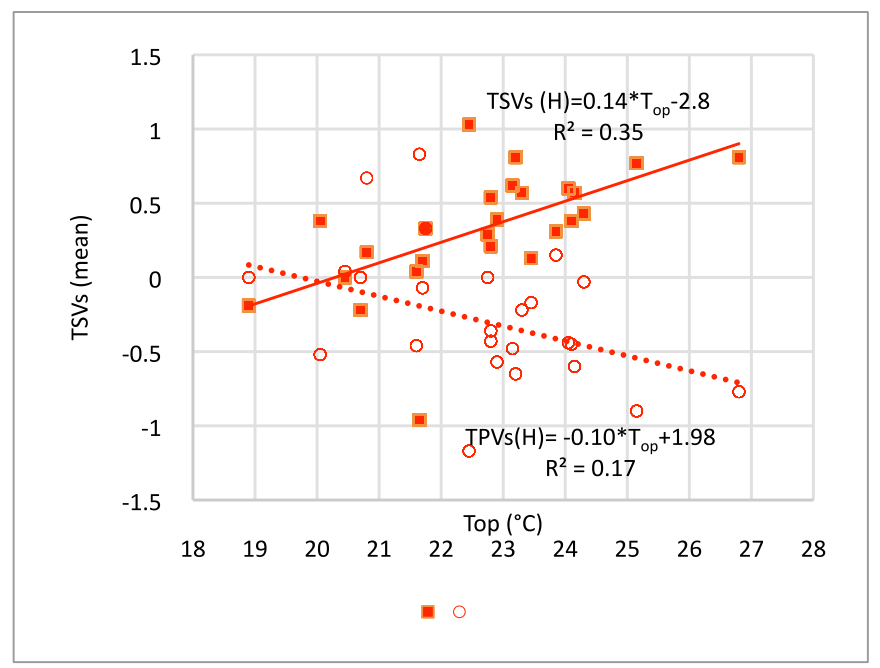

Fig. 9. Mean TSVs and TPVs against $\mathrm{T}_{\mathrm{op}}$ during heating seasons.

ear regression models, Figs. 8 and 9. Linear regression models are weighted according to the number of votes falling in each category of operative temperature. The intersection point of linear regression models suggests $\mathrm{T}_{\mathbf{C} \text { (children) }}$ of $20.9^{\circ} \mathrm{C}$ during non-heating seasons and $20.2^{\circ} \mathrm{C}$ during heating seasons. $\mathrm{T}_{\mathbf{C} \text { (children) }}$ derived from linear regression models validate the proposed method in this study (Figs. 5 and 6 ) to estimate comfort temperature. Results of a similar study show that comfort temperatures from Probit regression model $\left(\mathrm{T}_{\mathrm{op}}=22.2{ }^{\circ} \mathrm{C}\right)$ and linear regression model $\left(\mathrm{T}_{\mathrm{op}}=22.4^{\circ} \mathrm{C}\right)$ are similar [17].

Sensitivity: The regression slope is a measure of sensitivity to temperature changes [82]. The gradient of regression equation for linear models is inversely proportional to the adaptability of the building occupants [17]. A shallow gradient shows that subjects adapt more effectively to room temperature and accordingly their votes do not change quickly $[17,39]$. Figs. 8 and 9 suggest that children's adaptability to temperature changes is higher during nonheating seasons because slope of linear model is shallower during non-heating seasons $(b=0.09)$ than heating seasons $(b=0.14)$. Equation in Fig $8\left(\mathrm{TSV}_{\text {mean }}=0.09 \mathrm{~T}_{\mathrm{op}}-1.78\right)$ can be compared with equations in similar studies in Australia $\left(\mathrm{TSV}_{\text {mean }}=0.12 \mathrm{~T}_{\mathrm{op}}-2.88\right)$ [17] and China $\left(\mathrm{TSV}_{\text {mean }}=0.05 \mathrm{~T}_{\mathrm{op}}-0.96\right)$ [36] during summer. Figs. 8 and 9 show that a temperature change of $11.1^{\circ} \mathrm{C}$ is required to shift one score on thermal sensation scale during non-heating seasons, however, this change is $7.7^{\circ} \mathrm{C}$ during heating seasons.

\subsection{Adaptive behaviours}

\subsubsection{Personal adaptive behaviours}

Children in schools adapt themselves to the environment by a number of personal adaptive behaviours including changing clothing level [43,87-90], changing activity type and posture [18,91], drinking and fanning $[42,44]$. In this study, clothing, drinking and fanning behaviours of children were investigated by applying a questionnaire that was validated by the authors [76]. 'Cooling personal adaptive behaviours' in this study refer to all personal actions that children adopt to reach a cooler sensation. Fig. 10 shows proportion of cooling personal adaptive behaviours such as fanning, drinking cold water or not wearing jumper/cardigan. Fig. 10 shows that proportion of children who practice two and three cooling personal behaviours (total of $45.7 \%$ ) is higher during non-heating seasons and proportion of children who do not practice any cooling adaptive behaviour is higher during heating seasons (39.4\%) and

Fig. 11 shows the breakdown of cooling personal adaptive behaviours during non-heating and heating seasons. When children practice only one cooling personal adaptive behaviour, drinking cold water is the most frequent one, followed by taking off jumper/cardigan, Fig. 11. This is mainly because children have cold drinks frequently during breaks, after or before PE and assembly. When two personal behaviours are practised, the combination of having cold drink and removing jumper/cardigan has the highest frequency.

Children's Clothing Behaviour: To investigate how children's sensitivity for adaptive behaviours change in relation to comfort temperatures, Spearman correlation tests were run between 'clothing values' and ' $\mathrm{T}_{\text {diff }}$ '. Spearman Correlation which is a test to examine the relationship between an ordinal variable with skewed dependent variable [92,93] is used in this study.

Non-heating seasons: Children's clothing values and $\mathrm{T}_{\text {diff }}$ are significantly correlated during non-heating seasons (Spearman Correlation coefficient $=-0.3, P<0.001$ ). Fig. 12 shows that by increase in $\mathrm{T}_{\text {diff, }}$, the proportion of children wearing lighter levels of clothing [Clo value $=0.3$ and 0.39 ] increases significantly and the proportion of children wearing thicker layers of clothing decreases. At children's comfort temperature $\left(\mathrm{T}_{\text {diff }}=-1.9 \mathrm{~K}\right.$ and $\mathrm{T}_{\mathbf{C} \text { (children) }}=22.9^{\circ} \mathrm{C}$ ), average Clo value is around 0.58 , however, it decreases to 0.38 when $\mathrm{T}_{\mathrm{op}}$ is $6 \mathrm{~K}$ higher than $\mathrm{T}_{\mathbf{C}}$ (children) $\left(\mathrm{T}_{\text {diff }}=4 \mathrm{~K}\right.$ and $\left.\mathrm{T}_{\mathrm{op}}=28^{\circ} \mathrm{C}\right)$, Fig. 12 . Previous studies confirm that children's clothing level is correlated with running mean temperature, sequence of temperature, long term fluctuation in temperature [43,87-89] and operative temperature [32,89].

As can be seen in Table 7 , the proportion of children with a certain clothing value within the comfort band $\left(\mathrm{T}_{\mathbf{C} \text { (children) }} \pm 2 \mathrm{~K}\right.$ ) is more stable than that outside of the comfort band $\left(\mathrm{T}_{\text {diff }}>\mathrm{T}_{\mathbf{C}}\right.$ (children) $+2 \mathrm{~K}$ ). Standard Deviations (SDs) are significantly lower within comfort band than outside of it, Table 7. This finding confirms the suggested comfort band for children in this study. At upper limit of comfort band $\left(\mathrm{T}_{\text {diff }}=\mathrm{T}_{\mathbf{C} \text { (children) }}+2 \mathrm{~K}\right)$, there is a turning point in the proportion of children who follow a certain clothing behaviour, Fig. 12. At this point, the proportion of children who follow category $A$ (the lightest level of clothing) starts to increase, however, the proportion of children who follow categories B, C and D (the heavier levels of clothing) starts to decrease. According to Fig. 5, the proportion of children with warm sensation and cooler preference at the upper limit of comfort band $\left(\mathrm{T}_{\text {diff }}=+0.1\right.$ and $\left.\mathrm{T}_{\mathrm{op}} \approx 23^{\circ} \mathrm{C}\right)$ is $42 \%$, however, the proportion of children with the lightest clothing level is only $20 \%$ at this point. This suggests that higher proportion of children could potentially achieve thermal comfort at this point by adopting personal adaptive behaviours. 


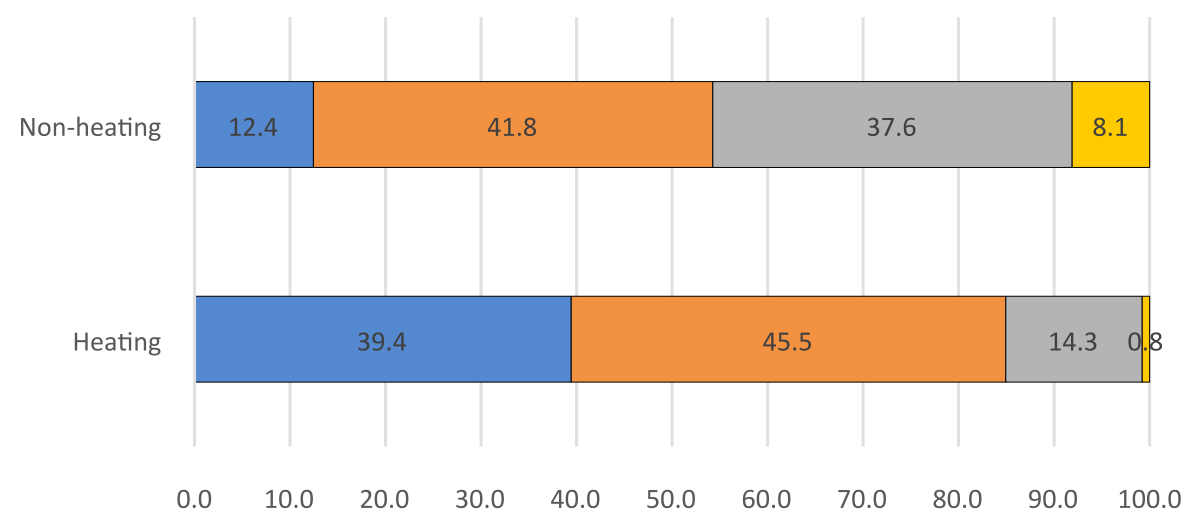

$\square$ No Adaptive Behaviour $\quad \square$ One Cooling Adaptive Behaviour

$\square$ Two Cooling Adaptive Behaviours $\square$ Three Cooling Adaptive Behaviours

Fig. 10. Proportion of cooling personal behaviours during non-heating and heating seasons.

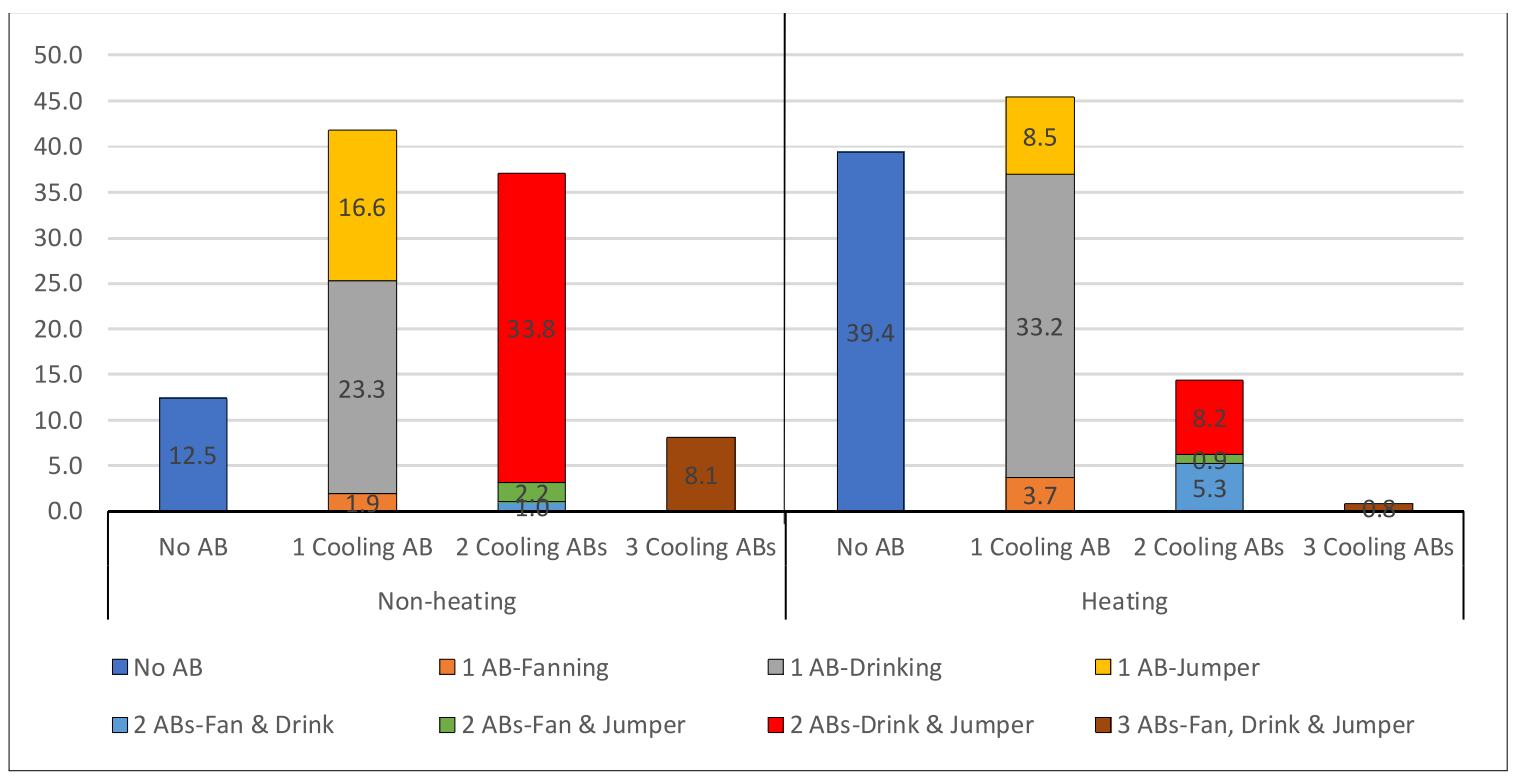

Fig. 11. Breakdown of cooling personal adaptive behaviours during non-heating and heating seasons.

Table 7

Proportion of children in categories of clothing within and outside of comfort band.

\begin{tabular}{|c|c|c|c|c|c|c|c|c|}
\hline \multirow[t]{3}{*}{ Categories for Clothing Values } & \multicolumn{8}{|c|}{ Proportion of children with a certain clothing level } \\
\hline & \multicolumn{4}{|c|}{ Within the comfort band $\left(\mathrm{T}_{\text {diff }}=\mathrm{T}_{\mathrm{C}(\text { children })} \pm 2\right)$} & \multicolumn{4}{|c|}{ Outside of the comfort band $\left(\mathrm{T}_{\text {diff }}>\mathrm{T}_{\mathrm{C}(\text { (children })}+2\right)$} \\
\hline & Mean & Minimum & Maximum & SD & Mean & Minimum & Maximum & SD \\
\hline Cat A [0.3 \& 0.39] & 12 & 9 & 18 & 3.2 & 48 & 20 & 83 & 22.6 \\
\hline Cat B [0.47 \& 0.49$]$ & 34 & 29 & 37 & 2.6 & 24 & 10 & 35 & 9.2 \\
\hline Cat C [0.55 \& 0.64] & 21 & 13 & 29 & 5.8 & 12 & 11 & 13 & 0.8 \\
\hline 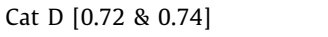 & 35 & 31 & 38 & 2.5 & 18 & 0 & 33 & 12.3 \\
\hline
\end{tabular}

Heating Season: Children's clothing values and $\mathrm{T}_{\text {diff }}$ are correlated during heating seasons (Spearman Correlation coefficient $=-0.1, P<0.01)$. However, the correlation is less significant than that during non-heating seasons because most of the children (76\%) have the same clothing values (0.72 or 0.74) during heating seasons, Fig. 4. Fig. 13 shows that by increase in $\mathrm{T}_{\mathrm{diff}}$, the proportion of children wearing lighter layers of clothing [value $=0.47$ and 0.49 ] increases and the proportion of children wearing thicker layers of clothing [value $=0.72$ and 0.74 ] decreases. At children's comfort temperature $\left(\mathrm{T}_{\text {diff }}=-2.8 \mathrm{~K}\right.$ and $\mathrm{T}_{\mathbf{C}}$ (children) $=20.2^{\circ} \mathrm{C}$ ), average Clo value is around 0.68 that is 0.1 higher than that during non-heating seasons (0.58). This can be amongst one of the reasons that $\mathrm{T}_{\mathbf{C} \text { (children) is lower during }}$ heating seasons $\left(20.2^{\circ} \mathrm{C}\right)$ than that during non-heating seasons $\left(20.9^{\circ} \mathrm{C}\right)$. By a $2 \mathrm{~K}$ increase from children's comfort temperature $\left(\mathrm{T}_{\mathrm{op}} \approx 22.5^{\circ} \mathrm{C}\right)$, the proportion of children in category $\mathrm{D}$ (the 


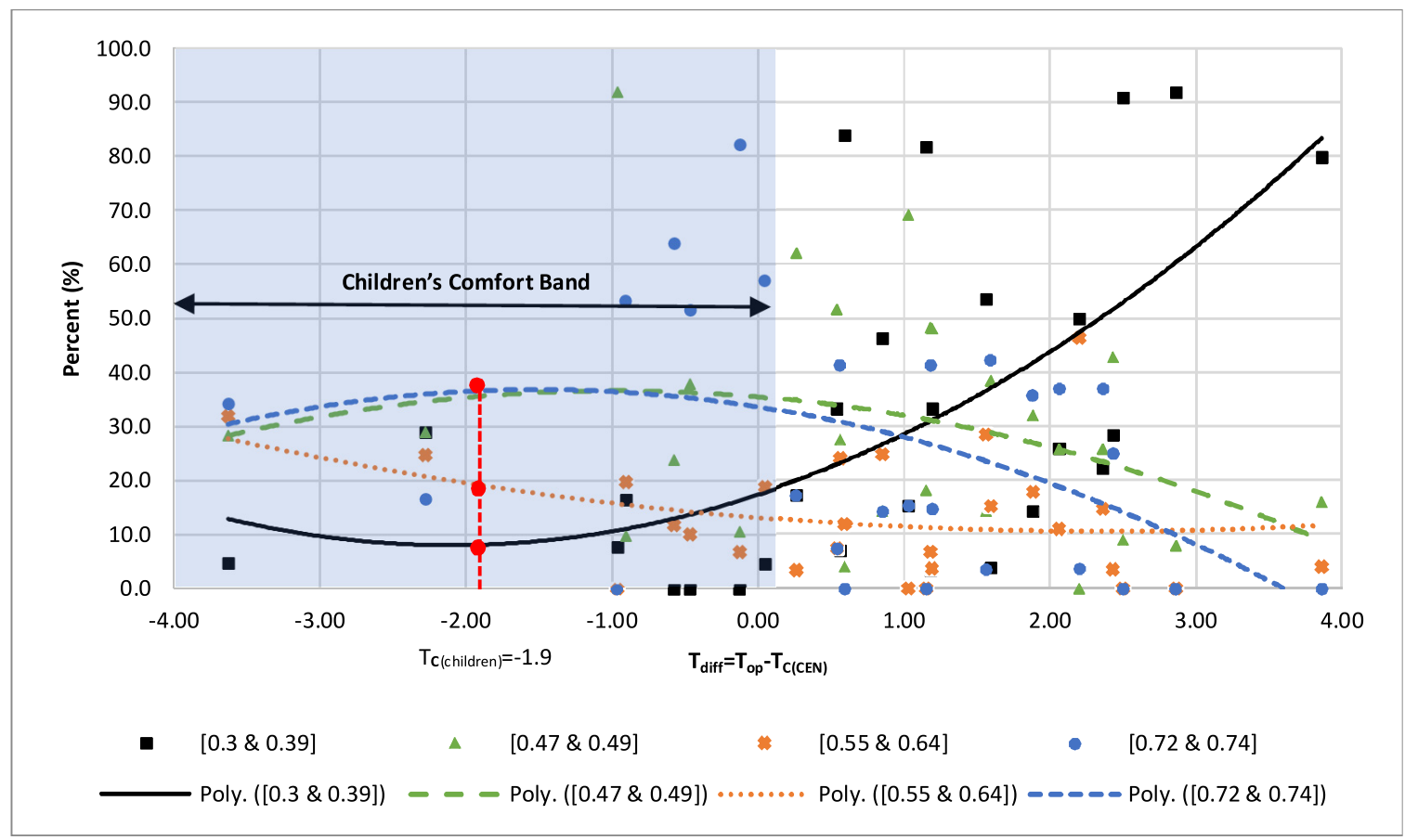

Fig. 12. Clothing values against $T_{\text {diff }}$ during non-heating seasons.

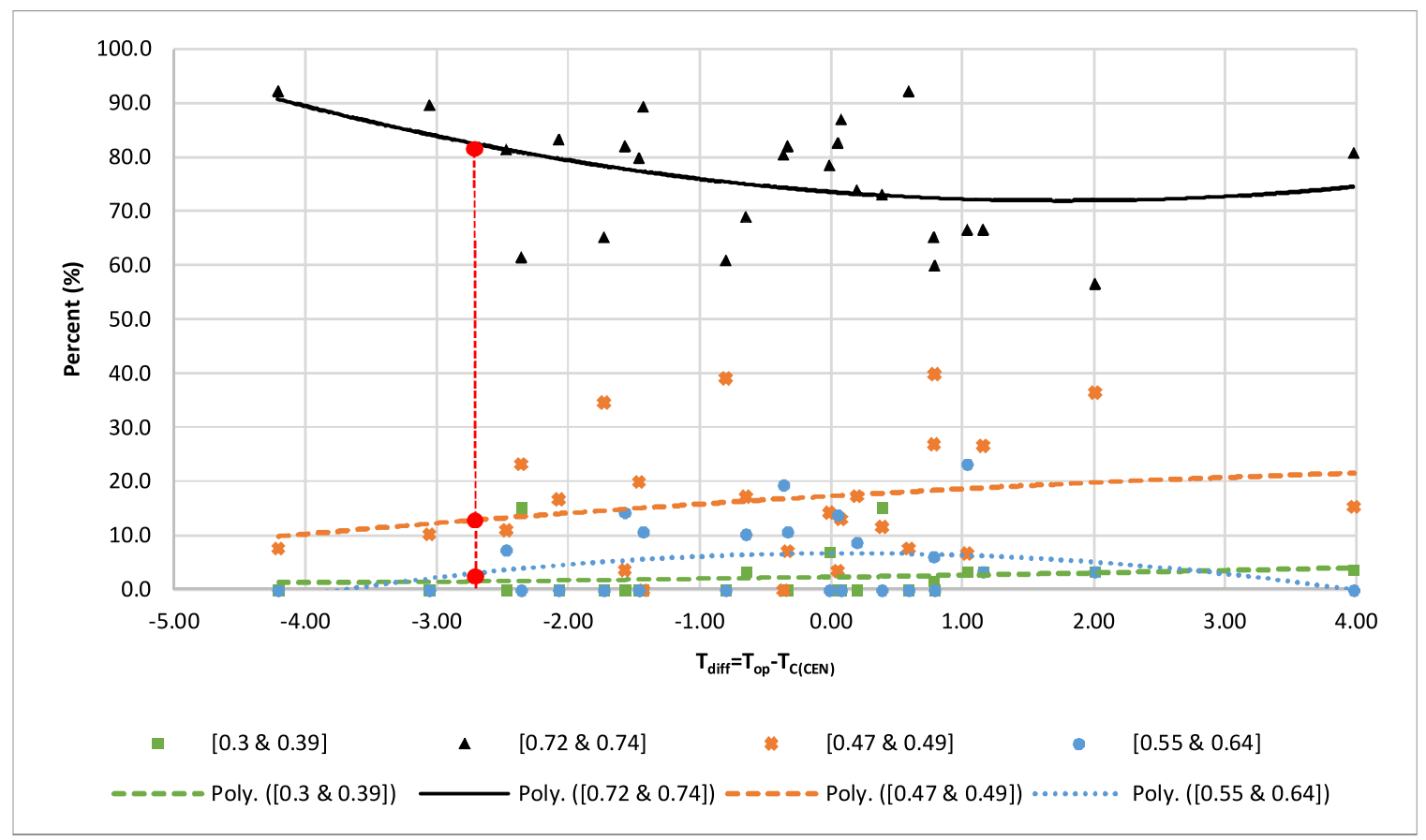

Fig. 13. Clothing values as a function of $\mathrm{T}_{\text {diff }}$ during heating seasons.

heaviest clothing level) drops only by $8 \%$. At this point, the proportion of children with warm sensation and cooler preference is $43 \%$. When $\mathrm{T}_{\mathrm{op}}$ is $6 \mathrm{~K}$ higher than $\mathrm{T}_{\mathbf{C} \text { (children) }}\left[\mathrm{T}_{\mathrm{op}} \approx 28^{\circ}(\mathrm{NH})\right.$ and $\mathrm{T}_{\mathrm{op}} \approx 26.5^{\circ} \mathrm{C}(\mathrm{H})$ ], average Clo value decreases 0.2 and 0.03 during non-heating and heating seasons, suggesting that children make fewer changes to their clothing uniform during heating seasons.

Cooling Personal Behaviours: The probability of practising cooling personal behaviours differs at different temperature intervals during non-heating seasons. Besides clothing adjustment, having cold drinks and fanning are also investigated as cooling per- sonal behaviours in Fig. 14. When children feel in discomfort, the proportion of them having cold drink is the highest, followed by choosing lighter levels of clothing and then fanning, Fig. 14. The proportion of children having cold drink is always high irrespective of temperature changes because having cold drink can be related to several other factors such as occupancy patterns, activity levels and thirst. The results show that $\mathrm{T}_{\text {diff }}$ is a statistically significant predictor of fanning (Logistic Regression coefficient $=-0.57$, $P<0.001)$ during non-heating seasons, however, it is not a predictor of fanning $(P=0.74)$ during heating seasons. Logistic regression 


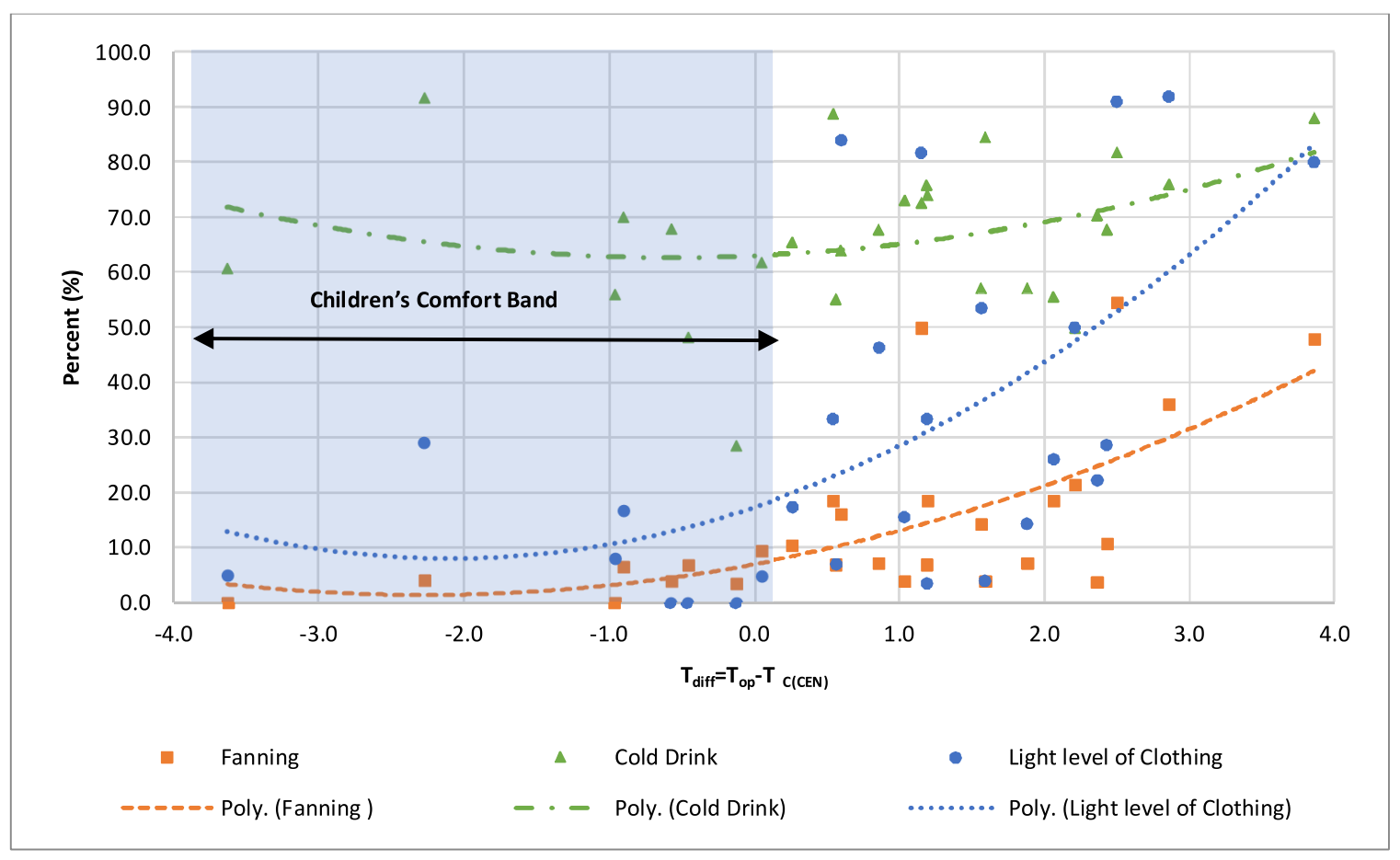

Fig. 14. Cooling personal behaviours against $T_{\text {diff }}$ during non-heating seasons.

Table 8

Changes in proportion of children engaged with personal adaptive behaviours.

\begin{tabular}{|c|c|c|c|c|c|}
\hline \multirow{3}{*}{ Behaviours } & \multicolumn{5}{|c|}{ Changes in proportion of children engaged with personal adaptive behaviours } \\
\hline & \multirow{2}{*}{$\frac{\text { Within Comfort Band }}{-3.9<\mathrm{T}_{\text {diff }}<+0.1}$} & \multicolumn{4}{|c|}{ Outside of Comfort Band when } \\
\hline & & $+0.1<\mathrm{T}_{\mathrm{diff}}<+1$ & $+1<\mathrm{T}_{\text {diff }}<+2$ & $+2<\mathrm{T}_{\text {diff }}<+3$ & $+3<\mathrm{T}_{\text {diff }}<+4$ \\
\hline Light clothing & $10 \%$ & $10 \%$ & $15 \%$ & $20 \%$ & $20 \%$ \\
\hline Fanning & $7 \%$ & $8 \%$ & $8 \%$ & $11 \%$ & $14 \%$ \\
\hline Cold drink & $10 \%$ & $2 \%$ & $5 \%$ & $6 \%$ & $7 \%$ \\
\hline
\end{tabular}

is suitable for testing relationships between a categorical outcome variable and one or more categorical or continuous predictor variables [94].

The proportion of children engaged with cooling behaviours has a turning point at the upper limit of comfort band $\left(\mathrm{T}_{\text {diff }}=\mathrm{T}_{\mathbf{C} \text { (children) }}+2 \mathrm{~K}, \mathrm{~T}_{\mathrm{op}} \approx 23^{\circ} \mathrm{C}\right)$. The speed of children's engagement with cooling behaviours within and outside of the comfort band is shown in Table 8. The speed of engagement is higher outside of the comfort band than inside of the band. The speed of engagement with clothing behaviour is higher than that with fanning and drinking behaviours, especially outside of the comfort band.

\subsubsection{Environmental adaptive behaviours}

Window Operation: Window operation as one of the most important environmental behaviours [95] was recorded using nonparticipant observation method which was validated by authors [76]. Results show that teachers or teacher assistants undertake around $78 \%$ of windows' adjustments, Fig. 15. Children carry out another $5 \%$ of adjustments which are requested by teachers. Around $16 \%$ of window operations are carried out directly by children and $2 \%$ of them are requested by children, Fig. 15 . In total, $82 \%$ of operations are carried out based on teachers' perception of thermal environment and $18 \%$ are done based on children's perception. Hence, teachers and teacher assistants are mainly in charge of operating windows, as supported in previous studies [31,44,96,97]. In only three of the studied classrooms (10\%) children were encouraged on environmental adaptive behaviours. among window operations done by children, $87 \%$ of adjustments were done in Schools 1,2 and 5 that have high potentials for window operation, Table 2.

Window Opening Temperature (WOT): To investigate how window operation in classrooms is related to thermal discomfort, window opening temperature (WOT) is compared with $\mathrm{T}_{\mathbf{C}(\mathrm{CEN})}$ and $\mathrm{T}_{\mathbf{C} \text { (children) }}$, Fig. 16. Temperatures at which windows were opened upon teacher's arrival to the classroom were removed from the database. A total number of 35 window openings during nonheating seasons and 20 window openings during heating seasons are presented in Fig. 16. Results show that among $97 \%$ of the cases during non-heating seasons and 80\% during heating seasons, WOT

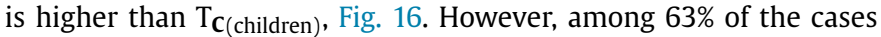
during non-heating seasons and 20\% during heating seasons, WOT is higher than adults' comfort temperature (WOT $>\mathrm{T}_{\mathbf{C}(\mathrm{CEN})}$ ).

Table 9 shows that among 63\% of the cases during non-heating seasons and $50 \%$ during heating seasons, the difference between WOT and $\mathrm{T}_{\mathbf{C} \text { (children) }}$ is more than $2 \mathrm{~K}$ (WOT- $\mathrm{T}_{\mathbf{C} \text { (children) }}>2 \mathrm{~K}$ ). Hence, more than half of the windows are opened at a temperature that is outside of the children's comfort band during non-heating seasons. However, almost all windows are opened within adults' comfort band during non-heating seasons (Only in 3\% of the cases,

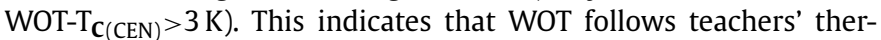
mal perception rather than children's thermal perception.

Open Area vs Comfort Temperature: The probability of opening windows as a function of thermal discomfort is estimated via calculating percent of open areas at 10 -min intervals against $\mathrm{T}_{\text {diff }}$, 


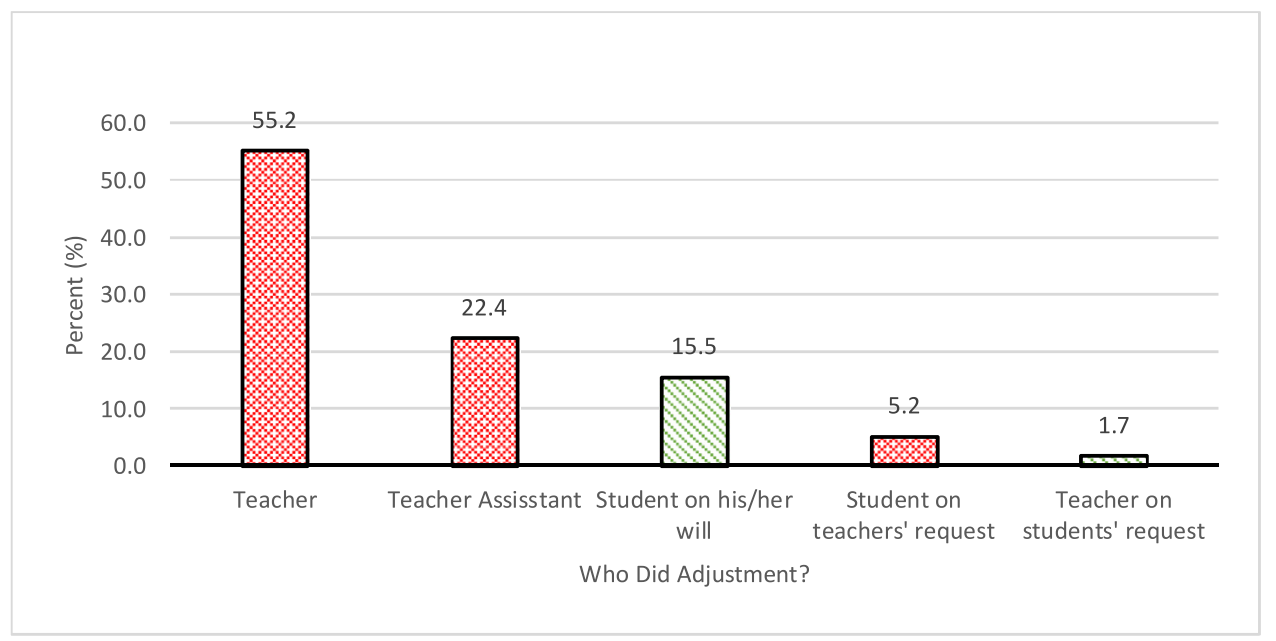

Fig. 15. Role of classrooms' occupants on window operation.

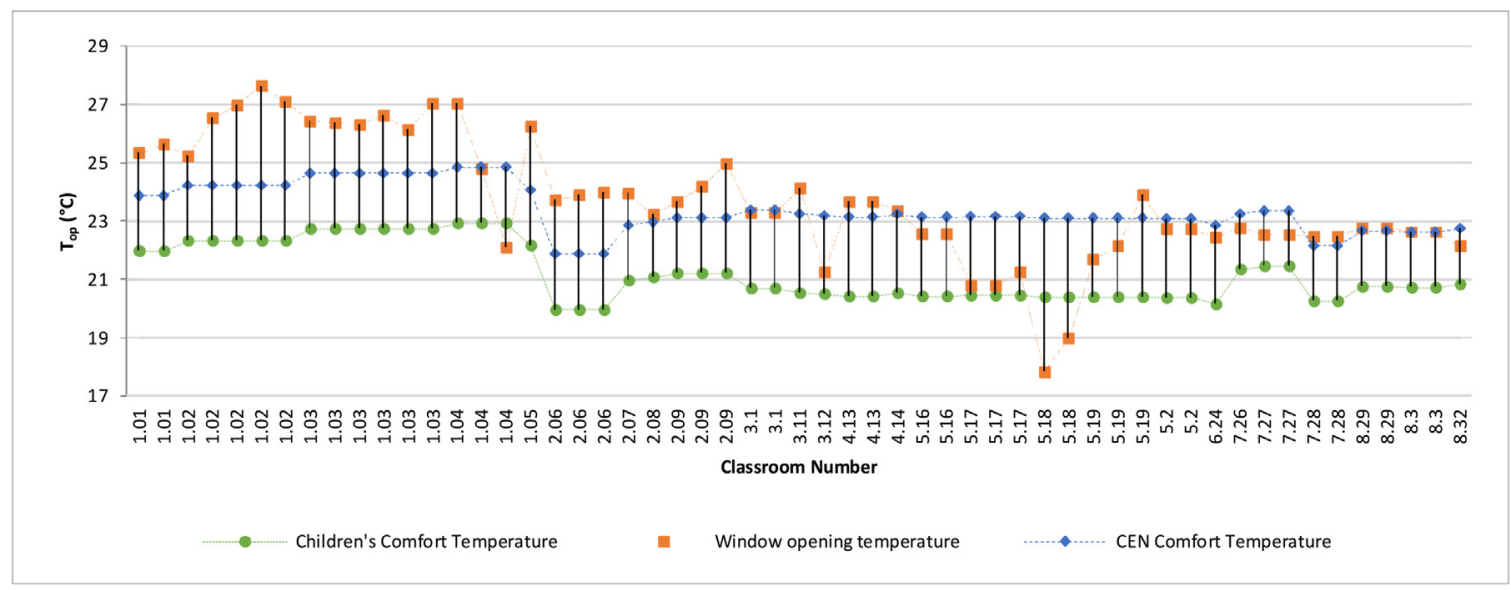

Fig. 16. The gap between WOT, $T_{\mathbf{C} \text { (children) }}$ and $T_{\mathbf{C}(C E N)}$.

Table 9

Relation between WOT, $\mathrm{T}_{\mathbf{C} \text { (CEN) }}$ and $\mathrm{T}_{\mathbf{C}_{\text {(children) }} \text {. }}$

\begin{tabular}{|c|c|c|c|c|}
\hline \multirow[t]{2}{*}{ Proportion of cases when ... } & \multicolumn{2}{|l|}{ Non-heating } & \multicolumn{2}{|l|}{ Heating } \\
\hline & Adults & Children & Adults & Children \\
\hline WOT $>\mathrm{T}_{\mathrm{C}}$ (WOT higher than $\mathrm{T}_{\mathrm{C}(\text { children })}$ and $\left.\mathrm{T}_{\mathrm{C}(\mathrm{CEN})}\right)$ & $22 / 35=63 \%$ & $34 / 35=97 \%$ & $4 / 20=20 \%$ & $16 / 20=80 \%$ \\
\hline WOT-T $\mathrm{T}_{\mathrm{C}(\mathrm{CEN})}>3 \mathrm{~K}$ (WOT Outside of adult's comfort band) & $1 / 35=3 \%$ & $21 / 35=60 \%$ & $0 / 20=0 \%$ & $4 / 20=20 \%$ \\
\hline
\end{tabular}

Fig. 17. As the size of operable areas is different in each classroom, percent of open areas (open windows and external doors) is considered for a more precise analysis of operations as a response to thermal discomfort. Results show that percent of open area and $\mathrm{T}_{\text {diff }}$ are significantly related during non-heating (Spearman Correlation coefficient $=0.32, P<0.001$ ) and heating seasons (Spearman Correlation coefficient $=0.5, P<0.001$ ). The proportion of open areas increases by increase in $T_{\text {diff }}$ and $T_{o p}$, as supported in previous studies in educational buildings [42,98-101]. Fig. 17 shows that the percent of open area is $30 \%$ at $\mathrm{T}_{\mathbf{C}(\mathrm{CEN})}$ and $22 \%$ at $\mathrm{T}_{\mathbf{C} \text { (children) during non-heating seasons. During heating sea- }}$ sons, the percent of open area is $50 \%$ at $\mathrm{T}_{\mathrm{C}(\mathrm{CEN})}$ and around $20 \%$ at $\mathrm{T}_{\mathbf{C} \text { (children), Fig. 17. The difference between percent of open area }}$ at $\mathrm{T}_{\mathbf{C} \text { (CEN) }}$ and $\mathrm{T}_{\mathbf{C} \text { (children) }}$ is around $10 \%$ during non-heating seasons and 30\% during heating seasons. During non-heating seasons, proportion of open area at upper limit of adults' comfort band

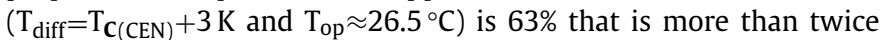
the proportion of open area (30\%) at upper limit of children's com- fort band $\left(\mathrm{T}_{\mathrm{diff}}=\mathrm{T}_{\mathrm{C} \text { (children) }}+2 \mathrm{~K}\right.$ and $\left.\mathrm{T}_{\mathrm{op}} \approx 23^{\circ} \mathrm{C}\right)$. This suggest that not only WOT is based on teachers' thermal perceptions, but also the proportion of open area is based on adults' thermal perceptions. When $\mathrm{T}_{\text {diff }}>-2.5$, the proportion of open area in relation to $T_{\text {diff }}$ is higher during heating seasons, suggesting teacher's more sensitivity to temperature changes during heating seasons than non-heating seasons.

\section{Discussion}

This study investigated thermal comfort and adaptive behaviours of primary school children during heating and nonheating seasons. The main findings of the study are listed below:

\subsection{Children's comfort temperature}

This study suggests $\mathrm{T}_{\mathrm{C}(\text { children) }}$ of $20.9^{\circ} \mathrm{C}$ during non-heating seasons and $20.2^{\circ} \mathrm{C}$ during heating seasons which are $1.9 \mathrm{~K}$ and 


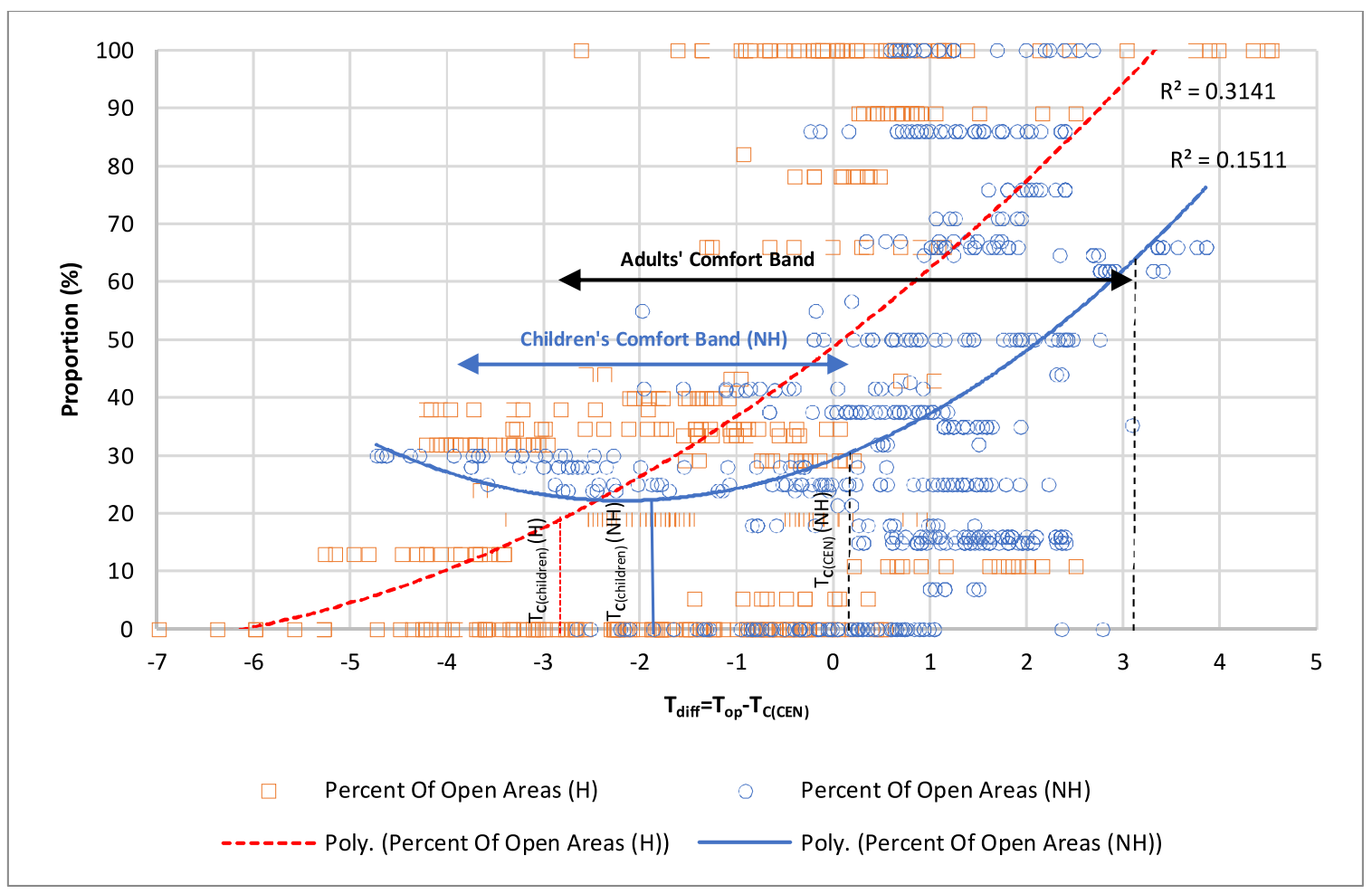

Fig. 17. Proportion of open area as a function of $\mathrm{T}_{\text {diff. }}$.

$2.8 \mathrm{~K}$ cooler than comfort temperature predicted by EN 15251 $\left(\mathrm{T}_{\mathbf{C}(\mathrm{CEN})}\right)$. A similar study on 7-11 years old children in UK suggests comfort temperature of $20.5^{\circ} \mathrm{C}$ during spring [31]. In a study in Australia during summer seasons, thermal comfort is found to be $1.5 \mathrm{~K}$ and $0.8 \mathrm{~K}$ cooler than comfort temperature predicted by ASHRAE in primary and secondary schools, respectively [86]. In another study in primary schools in the UK during summer, the proportion of children who feel comfortable and OK is the highest at $\mathrm{T}_{\text {diff }}=-3$ [44]. In a study in kindergartens in Korea from June to May, children's comfort temperature is $0.5^{\circ} \mathrm{C}$ and $3.3^{\circ} \mathrm{C}$ lower than that for adults during summer and winter, respectively [89]. In another study in elementary and high schools in Taiwan from September to January, comfort temperature is $1.7^{\circ} \mathrm{C}$ lower than that recommended by ASHRAE [34].

Children's thermal comfort in this study is lower than that for adults that is also supported in similar studies $[17,31,34,39,44,86,102]$. The discrepancy between children's and adults' comfort temperature can be explained by children's more limited adaptive behaviours [19,39] and their physical and physiological differences $[31,32,34,103-110,111]$. The main physical difference between children and adults affecting thermoregulation is children's higher surface-area-to mass-ratio [103,109,110], which results in a higher rate of heat absorption or loss [103]. The main physiological differences are children's higher metabolic rates per body weight $[32,89]$ and children's lower sweating rate [103,111]. Therefore, children are more sensitive to higher temperatures $[31,89]$ and they have a higher sensitivity to core temperature changes [110].

Results of this study show that children's comfort temperature during heating seasons is lower than that during non-heating seasons, as supported in similar studies in educational buildings [89,107]. Having higher comfort and preferred temperatures during non-heating seasons can be related to children's more practice of personal adaptive behaviours and exposure to more variant environmental conditions during non-heating seasons. Results show that children's preferred temperatures are $1.1 \mathrm{~K}$ and $0.4 \mathrm{~K}$ cooler than their comfort temperatures during non-heating and heating seasons. This discrepancy indicates that comfort temperature does not necessarily represent the preferred temperature of occupants, as supported in $[31,86]$.

\subsection{Adaptive behaviours}

Children practice personal adaptive behaviours more than environmental behaviours in this study; around $90 \%$ of the children during non-heating seasons and 60\% during heating seasons practice at least one cooling personal adaptive behaviour while only around $16 \%$ of window operations are done by children. A similar study in UK primary schools during non-heating season shows that $74 \%$ of children adopt personal behaviours and 19\% adopt environmental behaviours [44].

- Personal Behaviours: The proportion of children who adopt personal adaptive behaviours starts to increase when classroom temperature goes above children's comfort band during nonheating seasons. By $2 \mathrm{~K}$ increase from comfort temperature (at $\mathrm{T}_{\mathrm{op}} \approx 23^{\circ} \mathrm{C}(\mathrm{NH})$ and $\mathrm{T}_{\mathrm{op}} \approx 22.3^{\circ} \mathrm{C}(\mathrm{H})$ ) more than one-third (42$43 \%$ ) of the children feel 'warm or hot' with 'a bit cooler or cooler' preference. However, less than one-fifth of children have chosen lighter clothing levels at these temperatures. This suggests that children in discomfort could potentially be reduced by adopting effective personal behaviours. Around $40 \%$ of children during heating seasons and $12 \%$ during non-heating seasons practice no personal adaptive behaviours. These children need to be encouraged to adopt effective personal behaviours when feeling overheated, noting that $15 \%$ of children are overheated in this study. There are circumstances that restrict children's personal behaviours in schools, such as school dress codes, social background $[39,44,97,112]$ or limitations in modifying activity levels during teaching periods [39]. According to 
Fig. 12, children's personal behaviours start to increase significantly outside of the comfort band $\left(\mathrm{T}_{\text {diff }}>\mathrm{T}_{\mathbf{C} \text { (children) }}+2 \mathrm{~K}\right.$ ), suggesting that children are uncomfortable outside the $4 \mathrm{~K}$ band. Therefore, children's comfort band should not exceed $4 \mathrm{~K}$ which is also recommended by EN 15251 for category I buildings that accommodate vulnerable occupants. Another study supports that children have relatively smaller ranges of thermal comfort compared to adults [89].

- Environmental Behaviours: This study shows that operation of windows is mainly carried out by teachers (up to $77 \%$ ), also supported in $[31,44,96,97]$. Children are usually passive recipients of classroom conditions rather than active users [39]. One of the reasons that teachers usually decide for the entire classroom is that practising environmental adaptive behaviours in shared spaces with many occupants can be challenging, as supported in $[45,58,113,114]$. Children might disagree over preferred environmental behaviour, especially if one's adaptive behaviour results in someone else's local discomfort. This problem can be solved to some extent by providing more local controls [45]. There is a direct link between children's perception of thermal environment and their related adaptive behaviours [87]; more opportunities to control the environment make occupants more tolerant of uncomfortable conditions [82,90,115]. Therefore, lack of opportunities for controlling classroom environment results in students' increased level of dissatisfaction, especially at higher indoor temperatures [32,39].

The study highlights that windows' operation (i.e. WOT and the proportion of open window) is based on teachers' thermal perception. The proportion of open area is higher within adults' comfort band than children's comfort band. Furthermore, the difference between WOT and $\mathrm{T}_{\mathbf{C}}$ (children) is more than $2 \mathrm{~K}$ in more than half of the cases. This difference can be explained by following reasons: First, classrooms are mainly controlled by teachers who have higher comfort temperatures than children $[17,31,34,39,44,106,116]$. Second, children's reaction to the rise of temperature is slower than that for adults as children are less sensitive to temperature changes $[39,78,88,117]$. This is because children have faster heat loss rates [109] and higher metabolic rates [105,108]. Third, opportunities for practising effective environmental adaptive behaviours are not sufficiently provided for school children [45]. Fourth, teachers do not encourage children to engage in environmental adaptive behaviours. Fifth, teachers are not fully aware of their differences with children in perceiving thermal environment.

The findings suggest when $\mathrm{T}_{\mathrm{diff}}>-2.5$, the proportion of open area in relation to $T_{\text {diff }}$ is higher during heating seasons, Fig. 17. This can be explained by the following reasons: 1) School occupants practise fewer personal adaptive behaviours during heating seasons, therefore, environmental behaviours are adopted first. The sequence of adaptive behaviours can potentially be more efficient by adopting personal adaptive behaviours as the first reaction to thermal discomfort instead of opening windows at low outdoor temperatures during heating seasons. There is evidence that the sequence of practising adaptive behaviours can change energy consumption of the buildings [118]. 2) Windows in this study are opened at lower temperatures during heating seasons to improve indoor air quality, as supported in $[12,98,119-$ 121]. This can compromise thermal comfort by letting draughts in $[59,119,122,123]$ and result in heat loss and waste of energy [9,124]. 3) The temperature at which heating systems are operated during heating seasons can result in occupants' thermal discomfort and accordingly window opening. Therefore, heating setpoints need to be revised to provide children's pleasant thermal environment, reduce the number of overheated children and save energy. A similar study suggests that if students' comfort temperature is used for classrooms' heating, 12\% of heating energy can be saved [125].
Children's climatic adaptation to coldness should be considered in running classrooms during heating season [125].

\subsection{Sensitivity and adaptive behaviours}

This study confirms that children are more tolerant of temperature changes during non-heating seasons than heating seasons. It is found that TSV shifts one score by a temperature change of $11.1^{\circ} \mathrm{C}$ during non-heating seasons and $7.7^{\circ} \mathrm{C}$ during heating seasons. In another study in primary and secondary schools in Australia during summer, children's mean TSV shifts one point on the sevenpoint rating scale by the temperature change of $8^{\circ} \mathrm{C}$ [17]. Temperature change in this study is higher than that in [17] which can be attributed to the five-point rating scale used in this study and practice of personal adaptive behaviours. In similar studies, university students' TSV shifts one score by temperature change of $4.16 \mathrm{~K}$ in [126] and $6.39 \mathrm{~K}$ in [125]. This study suggests that children are less sensitive to temperature changes than adults, as supported in [39,78,117].

Children in this study have a higher comfort temperature and less sensitivity to temperature changes during non-heating seasons compared to heating seasons. Two reasons can be discussed for this finding: 1) The proportion of children engaged with personal behaviours of clothing, fanning and drinking is significantly higher during non-heating seasons. Reactions for adopting personal behaviours is slower during heating seasons; at $\mathrm{T}_{\text {diff }}=4 \mathrm{~K}$ only $26 \%$ of the children change their 'clothing level at comfort temperature', however, this number is $60 \%$ during non-heating seasons. Previous studies support that adaptive behaviours increase occupants' tolerance of high temperatures, uncomfortable conditions $[82,90,115,127]$, occupants' forgiveness and satisfaction [44,90,127131] and decease their reported discomfort [132]. 2) Evidence shows that thermal sensitivity can be affected by indoor and outdoor temperature variations [39] and by the difference between mean $\mathrm{T}_{\mathrm{op}}$ on survey day and $\mathrm{T}_{\mathrm{op}}$ at the time of filling out questionnaire [133]. More diverse thermal exposures in classrooms can possibly account for greater degrees of thermal sensitivity [17]. In this study, SDs for $\mathrm{T}_{\mathrm{op}}$ and $\mathrm{T}_{\text {out }}$ are higher during non-heating seasons $\left(\mathrm{SD}_{\mathrm{Top}}=2.1\right.$ and $\left.\mathrm{SD}_{\text {Tout }}=3.7\right)$ than heating seasons $\left(\mathrm{SD}_{\mathrm{Top}}=1.7\right.$ and $\mathrm{SD}_{\text {Tout }}=2.8$ ). Therefore, higher diversity of indoor and outdoor conditions during non-heating seasons can potentially contribute to children's higher adaptability, less sensitivity and also their acceptance of higher temperatures during non-heating seasons.

\section{Conclusion}

The results of this study are significant in improving the resilience of the UK primary schools in the light of climate change by understanding adaptive behaviours of school occupants.

Children's comfort temperature is found to be lower than that for adults. During heating seasons, children have a lower comfort temperature and they feel overheated quicker which can be attributed to fewer personal adaptive behaviours and more consistent environmental conditions during heating seasons. Around 15\% of children are overheated in both seasons, however, practice of personal and environmental behaviours is different in each season. During heating seasons, $40 \%$ of children practice no personal behaviours, however, the ones who adopt personal behaviours engage more slowly compared to the ones during non-heating seasons. Teachers are mainly in charge of environmental adaptive behaviours and classrooms are controlled based on their perception of thermal environment rather than children's perception. To deliver effective learning environments, providing opportunities for adaptive behaviours should be considered as a part of design process for both newly-built and refurbished schools. The study suggests that: 
- Schools designers should consider design strategies that can facilitate the efficient engagement of both teachers and children with controls.

- School protocols should encourage school occupants (teachers and children) to practise personal and environmental behaviours in an efficient sequence to reach comfort and save energy.

- Teachers should be informed about the gap between adults and children's thermal comfort.

- Teachers should encourage children to adopt effective personal and environmental behaviours when feeling in discomfort.

- Children should be informed about the impact of their adaptive behaviours on thermal sensations and energy consumption so that they consciously adopt adaptive behaviours.

- Children should be encouraged to communicate with their teachers about their thermal perception and their preference over controls.

\section{Declaration of Competing Interest}

None.

\section{CRediT authorship contribution statement}

Sepideh Sadat Korsavi: Conceptualization, Methodology, Validation, Formal analysis, Investigation, Visualization, Writing - original draft, Writing - review \& editing. Azadeh Montazami: Conceptualization, Visualization, Supervision, Resources, Writing - review \& editing, Funding acquisition.

\section{Acknowledgements}

The authors would like to acknowledge headteachers, teachers and children in studied primary schools in Coventry for their cooperation.

\section{Supplementary materials}

Supplementary material associated with this article can be found, in the online version, at doi:10.1016/j.enbuild.2020.109857.

\section{References}

[1] P. Wargocki, D. Wyon, The effects of moderately raised classroom temperatures and classroom ventilation rate on the performance of schoolwork by children, HVAC\&R Res. 13 (2007) 193-220, doi:10.1080/10789669.2007. 10390951.

[2] R. Ghaziani, Children's voices: raised issues for school design, CoDesign 4 (2008) 225-236, doi:10.1080/15710880802536403.

[3] G.A. Heath, M.J. Mendell, Do indoor environments in schools influence student performance? A review of the literature, A compil. Pap. Indoor air 2002 conf. Mem. Joan M. Daisey, 20, 2002 IV-20-26.

[4] M.J. Mendell, G.A. Heath, Do indoor pollutants and thermal conditions in schools influence student performance? A critical review of the literature, Indoor Air 15 (2005) 27-52, doi:10.1111/j.1600-0668.2004.00320.x.

[5] Z. Bakó-Biró, N. Kochhar, D.J. Clements-Croome, H.B. Awbi, M. Williams, Ventilation rates in schools and learning performance, Proc. Clim. (2007) 14341440 http://www.irbnet.de/daten/iconda/CIB7218.pdf.

[6] L. Chatzidiakou, D. Mumovic, A. Summerfield, $\mathrm{Is}^{\mathrm{CO}_{2}}$ a good proxy for indoor air quality in classrooms? Part 2: health outcomes and perceived indoor air quality in relation to classroom exposure and building characteristics, Build. Serv. Eng. Res. Technol. 36 (2015) 162-181, doi:10.1177/0143624414566245.

[7] M. Turunen, O. Toyinbo, T. Putus, A. Nevalainen, R. Shaughnessy, U. Haverinen-Shaughnessy, Indoor environmental quality in school buildings, and the health and wellbeing of students, Int. J. Hyg. Environ. Health 217 (2014) 733-739, doi:10.1016/j.ijheh.2014.03.002.

[8] R. Greene, M. Eftekhari, D. Clements-Croome, G. Georgiou, Measurements of $\mathrm{CO} 2$ levels in a classroom and its effect on the performance of the students, (2012). https://dspace.lboro.ac.uk/dspace-jspui/handle/2134/11458.

[9] D. Wyon, P. Wargocki, J. Toftum, G. Clausen, Classroom ventilation must be improved for better health and learning, Rehva. Eur. HVAC. J. 3 (2010) 12-16 (2010).
[10] R.J. Shaughnessy, U. Haverinen-Shaughnessy, A. Nevalainen, D. Moschandreas, A preliminary study on the association between ventilation rates in classrooms and student performance, Indoor Air 16 (2006) 465-468, doi:10.1111/ j.1600-0668.2006.00440.x.

[11] U. Haverinen-Shaughnessy, D.J. Moschandreas, R.J. Shaughnessy, Association between substandard classroom ventilation rates and students' academic achievement, Indoor Air 21 (2011) 121-131, doi:10.1111/j.1600-0668.2010. 00686.x.

[12] D.G. Shendell, R. Prill, W.J. Fisk, M.G. Apte, D. Blake, D. Faulkner, Associations between classroom $\mathrm{CO}_{2}$ concentrations and student attendance in Washington and Idaho, Indoor Air 14 (2004) 333-341, doi:10.1111/j.1600-0668.2004. 00251.x.

[13] L. Heschong, Daylighting and human performance, ASHRAE J. 44 (2002) 65-67.

[14] L. Heschong, Daylighting in Schools: aAn Investigation Into the Relationship Between Daylighting and Human Performance, 1999, p. 140. Detailed Report HMG-R-9803 http://eric.ed.gov/?id=ED444337

[15] S.A. Samani, The influence of light on student's learning performance in learning environments: a knowledge internalization perspective, World Acad. Sci. Eng. Technol. 81 (2011) 540-547 http://www.scopus.com/inward/record. url?eid=2-s2.0-80053454150\&partnerID=tZOtx3y1.

[16] N.P. Sensharma, J.E. Woods, A.K. Goodwin, Relatoinships between the indoor environment and productivity: a literature review, ASHRAE Trans. 104 (1998) 686-701.

[17] R. De Dear, J. Kim, C. Candido, M. Deuble, Adaptive thermal comfort in australian school classrooms, Build. Res. Inf. 43 (2015) 383-398, doi:10.1080/ 09613218.2015.991627.

[18] F. Nicol, M. Humphreys, S. Roaf, Adaptive Thermal Comfort: Principles and Practice, Routledge, 2012.

[19] Y. Wang, J. Kuckelkorn, F.Y. Zhao, D. Liu, A. Kirschbaum, J.L. Zhang, Evaluation on classroom thermal comfort and energy performance of passive school building by optimizing HVAC control systems, Build. Environ. 89 (2015) 86106, doi:10.1016/j.buildenv.2015.02.023.

[20] E. Jago, K. Tanner, Influence of the school facility on student achievement, Retrieved May. 31 (1999) 2004.

[21] J.A. Lackney, The relationship between environmental quality of school facilities and student performance: a congressional briefing to the US house of representatives committee on science, (1999).

[22] U. Haverinen-Shaughnessy, M. Turunen, J. Metsämuuronen, J. Palonen, T. Putus, J. Kurnitski, R. Shaughnessy, Health and academic performance of sixth grade students and indoor environmental quality in Finnish elementary schools, Br. J. Educ. Res. 2 (2012) 42-58.

[23] P. Wargocki, J. Sundell, W. Bischof, G. Brundrett, P.O. Fanger, F. Gyntelberg, S.O. Hanssen, P. Harrison, A. Pickering, O. Seppänen, The role of ventilation and HVAC systems for human health in nonindustrial indoor environments. A supplementary review by EUROVEN group, Indoor (2002) 33-38 (2002).

[24] O. Seppanen, W.J. Fisk, Q.H. Lei, Ventilation and work performance in office work, (2005).

[25] I. Holmberg, D. Wyon, The dependence of performance in school on classroom temperature, department of educational and psychological research, School Educ. (1969).

[26] DfE, Building Bulletin 101: guidelines on ventilation, thermal comfort and indoor air quality in schools, Dep. Educ 1-62 (2016) 011-2711642.

[27] F. Nicol, M. Humphreys, Derivation of the adaptive equations for thermal comfort in free-running buildings in European standard EN15251, Build. Environ. 45 (2010) 11-17, doi:10.1016/j.buildenv.2008.12.013.

[28] ASHRAE, ANSI/ASHRAE 55:2013 Thermal environmental conditions for human occupancy, 2013. ISSN 1041-2336.

[29] A. Auliciems, Thermal requirements of secondary schoolchildren in winter, J. Hyg. 67 (1969) 59-65, doi:10.1017/S0022172400041425.

[30] A. Auliciems, Thermal sensations of secondary schoolchildren in summer, J. Hyg. 71 (1973) 453-458, doi:10.1017/S002217240004643X.

[31] D. Teli, M.F. Jentsch, P.A.B.B. James, Naturally ventilated classrooms: an assessment of existing comfort models for predicting the thermal sensation and preference of primary school children, Energy Build. 53 (2012) 166-182, doi:10.1016/j.enbuild.2012.06.022.

[32] H. Yun, I. Nam, J. Kim, J. Yang, K. Lee, J. Sohn, A field study of thermal comfort for kindergarten children in korea: an assessment of existing models and preferences of children, Build. Environ. 75 (2014) 182-189, doi:10.1016 j.buildenv.2014.02.003.

[33] A. Auliciems, Warmth and comfort in the subtropical winter: a study in brisbane schools, J. Hyg. 74 (1975) 339-343, doi:10.1017/S0022172400046854.

[34] R.-.L. Hwang, T.-P. Lin, C.-.P. Chen, N.-J. Kuo, Investigating the adaptive mode of thermal comfort for naturally ventilated school buildings in Taiwan, Int. J. Biometeorol. 53 (2009) 189-200, doi:10.1007/s00484-008-0203-2.

[35] H.H. Liang, T.P. Lin, R.L. Hwang, Linking occupants' thermal perception and building thermal performance in naturally ventilated school buildings, Appl. Energy 94 (2012) 355-363 10.1016/j.apenergy.2012.02.004.

[36] G. Zhang, C. Zheng, W. Yang, Q. Zhang, D.J. Moschandreas., D.J. Moschandreas, Thermal comfort investigation of naturally ventilated classrooms in a subtropical region, Indoor Built Environ. 16 (2007) 148-158 $10.1177 / 1420326$ X06076792.

[37] A. Kwok, J. Reardon, K. Brown, Thermal comfort in tropical classrooms/Discussion, ASHRAE Trans. (1998) http://search.proquest.com/ openview/c40ec10524ad71 ebde277b73ee0b9921/1?pq-origsite=gscholar. 
[38] S.S. Khoo, N.H. Wong, S.S. Khoo, Thermal comfort in classrooms in the tropics, Energy Build. 35 (2003) 337-351 10.1016/S0378-7788(02)00109-3.

[39] S. Haddad, P. Osmond, S. King, Revisiting thermal comfort models in Iranian classrooms during the warm season, Build. Res. Inf. (2016) 1-17 10.1080/09613218.2016.1140950.

[40] R. de Dear, G.S. Brager, Developing an adaptive model of thermal comfort and preference, ASHRAE Trans. 104 (1998) 1-18.

[41] A. Heebøll, P. Wargocki, Jø. Toftum, Window and door opening behavior, carbon dioxide concentration, temperature, and energy use during the heating season in classrooms with different ventilation retrofits-ASHRAE RP1624, Sci. Technol. Built Environ. 4731 (2018) 1-12, doi:10.1080/23744731.2018.1432938.

[42] S.S. Korsavi, A. Montazami, Adaptive behaviours and occupancy patterns in UK primary schools: impacts on comfort and indoor quality, in: Wind. Conf. Rethink. Comf., 2018, pp. 627-639. http://windsorconference.com/ proceedings/.

[43] J.F. Nicol, M.A. Humphreys, Thermal comfort as part of a self-regulating system, Build. Res. Pract. 1 (1973) 174-179, doi:10.1080/09613217308550237.

[44] A. Montazami, M. Gaterell, F. Nicol, M. Lumley, C. Thoua, Developing an algorithm to illustrate the likelihood of the dissatisfaction rate with relation to the indoor temperature in naturally ventilated classrooms, Build. Environ. 111 (2017) 61-71, doi:10.1016/j.buildenv.2016.10.009.

[45] S.S. Korsavi, A. Montazami, J. Brusey, Developing a design framework to facilitate adaptive behaviours, Energy Build. 179 (2018) 360-373, doi:10.1016/j. enbuild.2018.09.011.

[46] National Adaptation Programme, The National Adaptation Programme Making the country resilient to a changing climate, 2013. https: //assets.publishing.service.gov.uk/government/uploads/system/uploads attachment_data/file/727259/pb13942-nap-20130701.pdf.

[47] M. Kottek, J. Grieser, C. Beck, B. Rudolf, F. Rubel, World map of the Köppen-Geiger climate classification updated, Meteorol. Zeitschrift. 15 (2006) 259-263.

[48] Weather Observations Website, http://wow.metoffice.gov.uk/, (n.d.). http://wow.metoffice.gov.uk/ (accessed December 20, 2017).

[49] A. Montazami, M. Wilson, F. Nicol, Aircraft noise, overheating and poor air quality in classrooms in London primary schools, Build. Environ. 52 (2012) 129-141, doi:10.1016/j.buildenv.2011.11.019.

[50] CIBSE, ventilation and ductwork, Guid. B2. (2016). 10.1002/9780470054581.eib608.

[51] Extrium, England noise map viewer, (2015). http://www.extrium.co.uk/ noiseviewer.html.

[52] DfES, Building bulletin 93. A design guide: acoustic design for schools. London., 2003.

[53] Metoffice, pollution forecast, UK AIR Air Inf. Resour. (2017) https://uk-air. defra.gov.uk/forecasting/locations?.

[54] J.L. Sze, Indoor environmental conditions in new york city public school classrooms, a survey., (2009).

[55] A. Slater, Occupant use of lighting controls - a review of current practice, problems and how to avoid them, Fuel Energy Abstr. 37 (1996) 237 http://www.sciencedirect.com/science/article/B6V39-3WRJ2D4-18T/1/ 3ce7ce805be90b8a79d46fd3f9ac49eb.

[56] L. Sanati, M. Utzinger, The effect of window shading design on occupant use of blinds and electric lighting, Build. Environ. 64 (2013) 67-76, doi:10.1016/j. buildenv.2013.02.013.

[57] D. Maniccia, B. Rutledge, M. Rea, W. Morow, in: Occupant Use of Manual Lighting Controls in Private Offices.pdf, Iesna, 1999, pp. 489-512, doi:10.1080/ 00994480.1999 .10748274$.

[58] P.R. Boyce, Observations of the manual switching of lighting, Light. Res. Technol. 12 (1980) 195-205, doi:10.1177/096032718001200403.

[59] P. Bailey, G. Hudson, Acoustic and ventilation assessment is necessary, (2013) 43-44.

[60] D. Lindelöf, N. Morel, A field investigation of the intermediate light switching by users, Energy Build. 38 (2006) 790-801, doi:10.1016/j.enbuild.2006.03.003.

[61] E. Gratia, I. Bruyere, A. De Herde, How to use natural ventilation to cool narrow office buildings, Build. Environ. 39 (2004) 1157-1170.

[62] T. CIBSE, Minimising pollution at air intakes., 1999.

[63] CIBSE, Energy benchmarks, 2008. 1122.

[64] DfE, Department for education and skills (DfES), building bulletin 101: guidelines on ventilation, thermal comfort and indoor air quality in schools, Dep. Educ. 1-62 (2016) 011-2711642.

[65] T.S. Larsen, P. Heiselberg, Single-sided natural ventilation driven by wind pressure and temperature difference, 40 (2008) 1031-1040. 10.1016/j.enbuild.2006.07.012.

[66] A.C. Pitts, S. Georgiadis., "Ventilation air flow through window openings in combination with shading devices.," 1994. https://www.osti.gov/etdeweb/ biblio/80849.

[67] RCPCH, UK-World Health Organisation growth charts - 2-18 years, (n.d.). https://www.rcpch.ac.uk/resources/ uk-world-health-organisation-growth-charts-2-18-years.

[68] S.A. Ghita, T. Catalina, Energy efficiency versus indoor environmental quality in different Romanian countryside schools, Energy Build. 92 (2015) 140-154, doi:10.1016/j.enbuild.2015.01.049.

[69] N. Borgers, E. De Leeuw, J. Hox, Children as respondents in survey research: cognitive development and response quality, Bull. Methodol. Sociol. 66 (2000) 60-75, doi:10.1093/jpepsy/25.1.56.

[70] S. Haddad, S. King, P. Osmond, S Heidari, Questionnaire design to determine c hildren 's thermal sensation, preference and acceptability in the classroom, in: 28th conf. Oppor. Limits Needs Towar. An Environ. Responsible Archit., 1 2012, p. 2.

[71] K. Fabbri, Indoor thermal comfort perception: a questionnaire approach focusing on children, 2015. 10.1007/978-3-319-18651-1.

[72] SWEMA, Measuring instruments, 2014. http://www.hsingnan.com.tw/images/ inst/SWEMA/Swema2014.pdf.

[73] EasyLog, temperature, humidity and dew point data logger, 2016. https:// www.lascarelectronics.com/media/1572/easylog-data-logger_el-usb-2.pdf.

[74] ISO 7726, Ergonomics of the thermal environment-instruments for measuring physical quantities, 2001. 10.3403/02509505.

[75] ISO, ISO 7730, Ergonomics of the thermal environment analytical determination and interpretation of thermal comfort using calculation of the PMV and PPD indices and local thermal comfort criteria, Management 3 (2005) 605615, doi:10.1016/j.soildyn.2004.11.005.

[76] S.S. Korsavi, A. Montazami, Developing a valid method to study adaptive behaviours with regard to IEQ in primary schools, Build. Environ. 153 (2019) 1-16, doi:10.1016/j.buildenv.2019.02.018.

[77] T. Goto, J. Toftum, R. De Dear, Thermal sensation and comfort with transient metabolic rates, (2002) 1038-1043.

[78] D. Teli, M.F. Jentsch, P.A.B. James, A.S. Bahaj, Field study on thermal comfort in a UK primary school, in: Proc. 7th Wind. Conf. Chang. Context Comf. an Unpredictable World Cumberl. Lodg. Wind. UK, 7730, 2012, pp. 12-15.

[79] CEN (European Committee for Standardization), EN 15251: indoor environmental input parameters for design and assessment of energy performance of buildings addressing indoor air quality, thermal environment, lighting and acoustics, Geneva Int. Stand. Organ. (2007) 54, doi:10.1520/E2019-03R13. Copyright.

[80] P.O. Fanger, Thermal comfort. analysis and applications in environmental engineering., Comf. Anal. Appl. Environ. (1970) http://www. cabdirect.org/abstracts/19722700268.html\%255Cnpapers2://publication/uuid/ 5CE163C3-F9AC-4937-A143-1238F1D806C5.

[81] J.F. Nicol, M.A. Humphreys, Adaptive thermal comfort and sustainable thermal standards for buildings, Energy Build. 34 (2002) 563-572 10.1016/S0378-7788(02)00006-3.

[82] M. a. Humphreys, J.F. Nicol, I. a. Raja, F.J. Nicol, I. a. Raja, Field studies of indoor thermal comfort and the progress of the adaptive approach, Adv. Build. Energy Res. 1 (2007) 55-88, doi:10.1080/17512549.2007.9687269.

[83] M. Humphreys, F. Nicol, S. Roaf, Adaptive thermal comfort: foundations and analysis, 2015 https://books.google.co.uk/books?hl=en\&lr=\&id=vOdzCgAAQBAJ\&oi=fnd\&pg= PP1\&dq=Adaptive+Thermal+Comfort+Foundations+and+analysis.\&ots= WfegU4J6CS\&sig=UgT6fU0NkSX-x7bilvtu7hmmfTw (accessed November 3, 2016).

[84] M. Humphreys, Outdoor temperatures and comfort indoors, 6 (1978) 92-105 $10.1080 / 09613217808550656$.

[85] CIBSE, Guide A, Environmental Design, seventh ed. , Chartered Institution of Building Services Engineers, London, 2006.

[86] J. Kim, R. de Dear, Thermal comfort expectations and adaptive behavioural characteristics of primary and secondary school students, Build. Environ. 127 (2018) 13-22

[87] M.A. Humphreys, Classroom temperature, clothing and thermal comfort - a study of secondary school children in summertime, Repr. from Build. Serv. Eng. 41 (1974) 191-202.

[88] M.A. Humphreys, A study of the thermal comfort of primary school chilrdren in summer, Build. Environ. 12 (1977) 231-239.

[89] I. Nam, J. Yang, D. Lee, E. Park, J. Sohn, A study on the thermal comfort and clothing insulation characteristics of preschool children in Korea, Build. Environ. 92 (2015) 724-733, doi:10.1016/j.buildenv.2015.05.041.

[90] A.G. Kwok, C. Chun, Thermal comfort in Japanese schools, Sol. Energy 74 (2003) 245-252, doi:10.1016/S0038-092X(03)00147-6.

[91] I.A. Raja, F. Nicol, A technique for recording and analysis of postural changes associated with thermal comfort [Technical note], Appl. Ergon. 28 (1997) 221 225, doi:10.1016/S0003-6870(96)00036-1.

[92] E. Mccrum-gardner, Which is the correct statistical test to use ?, 46 (2008) 38-41. 10.1016/j.bjoms.2007.09.002.

[93] A. Bryman, D. Cramer, with SPSS 12 and 13, n.d.

[94] C.J. Peng, K.L. Lee, G.M. Ingersoll, C.J. Peng, K.L. Lee, G.M.I. An, C.J. Peng, G.M. Ingersoll, An Introduction to Logistic Regression Analysis and Reporting, 0671, 2002, pp. 2-14, doi:10.1080/00220670209598786.

[95] H.B. Rijal, P. Tuohy, M.A. Humphreys, J.F. Nicol, A. Samuel, J. Clarke, Using results from field surveys to predict the effect of open windows on thermal comfort and energy use in buildings, Energy Build. 39 (2007) 823-836, doi:10.1016/j.enbuild.2007.02.003.

[96] V. De Giuli, O. Da Pos, M. De Carli, Indoor environmental quality and pupil perception in Italian primary schools, Build. Environ. 56 (2012) 335-345, doi:10.1016/j.buildenv.2012.03.024.

[97] A. Michael, J.F. Nicol, Understanding the adaptive approach to thermal comfort, (1998).

[98] M. Santamouris, A. Synnefa, M. Asssimakopoulos, I. Livada, K. Pavlou, M. Papaglastra, N. Gaitani, D. Kolokotsa, V. Assimakopoulos, Experimental investigation of the air flow and indoor carbon dioxide concentration in classrooms with intermittent natural ventilation, Energy Build. 40 (2008) 18331843, doi:10.1016/j.enbuild.2008.04.002.

[99] F. Stazi, F. Naspi, M. D’Orazio, Modelling window status in school classrooms Results from a case study in Italy, Build. Environ. 111 (2017) 24-32, doi:10. 1016/j.buildenv.2016.10.013. 
[100] S. Dutton, L. Shao, Window opening behaviour in a naturally ventilated school, in: Proc. 4th Natl. Conf. IBPSA- ...., 2010, pp. 260-268. http://www. ibpsa.us/pub/simbuild2010/papers/SB10-DOC-TS05B-02-Dutton.pdf.

[101] V. Fabi, R.V. Andersen, S. Corgnati, B.W. Olesen, Occupants' window opening behaviour: a literature review of factors influencing occupant behaviour and models, Build. Environ. 58 (2012) 188-198, doi:10.1016/j.buildenv.2012.07.009.

[102] D. Teli, P.A.B. James, M.F. Jentsch, Investigating the principal adaptive comfort relationships for young children, Build. Res. Inf. 43 (2015) 371-382, doi:10. 1080/09613218.2015.998951.

[103] B. Falk, Effects of thermal stress during rest and exercise in the paediatric population, I (1998) 221-240.

[104] S.P. Corgnati, R. Ansaldi, M. Filippi, Thermal comfort in italian classrooms under free running conditions during mid seasons: assessment through objective and subjective approaches, Build. Environ. 44 (2009) 785-792, doi:10. 1016/j.buildenv.2008.05.023.

[105] G. Havenith, Metabolic rate and clothing insulation data of children and adolescents during various school activities, Ergonomics 50 (2007) 1689-1701, doi:10.1080/00140130701587574

[106] D. Teli, P.A.B.B. James, M.F. Jentsch, Thermal comfort in naturally ventilated primary school classrooms, Build. Res. Inf. 41 (2013) 301-316, doi:10.1080/ 09613218.2013 .773493$.

[107] M. Trebilcock, J. Soto, R. Figueroa, Thermal comfort in primary schools : a field study in Chile, in: Proc. 8th Wind. Conf. Count. Cost Comf. a Chang. World Cumberl. Lodg. Wind. UK, 10-13 April 2014, 2012, pp. 10-13.

[108] H. Frumkin, R.J. Geller, I.L. Rubin, J Nodvin, Safe and Healthy School Environments, Oxford University Press, 2006.

[109] E.A. Mccullough, S. Eckels, C. Harms, Determining temperature ratings for children ' $\mathrm{s}$ cold weather clothing, 40 (2009) 870-877. 10.1016/j.apergo.2008.12.004.

[110] G.S. Anderson, Thermoregulatory responses of circumpubertal children, (1996). 10.1007/BF02337720.

[111] B. Falk, R. Dotan, Symposium / symposium children 's thermoregulation during exercise in the heat - a revisit, (2008). 10.1139/H07-185.

[112] A. Montazami, M. Gaterell, F. Nicol, M. Lumley, C. Thoua, Impact of social background and behaviour on children's thermal comfort, Build. Environ. 122 (2017) 422-434, doi:10.1016/j.buildenv.2017.06.002.

[113] B. Bordass, Daylight use in open-plan offices - The opportunities and the fantasies, Fuel Energy Abstr. 36 (1995) 265 http: //www.sciencedirect.com/science/article/B6V39-3YVMYK5-3KF/1/ 3b621b10af471965dd7c1d1a4e8ec893.

[114] A.K. Kapsis, K. O'Brien, W. Athienitis, Time-lapse photography and image recognition to monitor occupant-controlled shade patterns: analysis and results, SMR 1 (1) (2013) 2.

[115] G.S. Brager, G. Paliaga, R. de Dear, Operable windows, personal control and comfort, ASHRAE Trans. 110 (2004) 1-20.

[116] D. Teli, M.F. Jentsch, P.A.B.B. James, The role of a building's thermal properties on pupils' thermal comfort in junior school classrooms as determined in field studies, Build. Environ. 82 (2014) 640-654, doi:10.1016/j.buildenv.2014.10.005.
[117] M.A.A. Humphreys, A study of the thermal comfort of primary school children in summer, Build. Environ. 12 (1977) 231-239, doi:10.1016/0360-1323(77) 90025-7.

[118] R.V. Andersen, B.W. Olesen, J. Toftum, Modeling window opening behaviour in Danish dwellings, in: Proc. 12th Int. Conf. Indoor Air Qual. Clim, 2011.

[119] J. Gao, P. Wargocki, Y Wang, Ventilation system type, classroom environmental quality and pupils' perceptions and symptoms, Build. Environ. 75 (2014) 46-57, doi:10.1016/j.buildenv.2014.01.015.

[120] L. Stabile, M. Dell'Isola, A. Frattolillo, A. Massimo, A. Russi, Effect of natural ventilation and manual airing on indoor air quality in naturally ventilated Italian classrooms, Build. Environ. 98 (2016) 180-189, doi:10.1016/j.buildenv. 2016.01.009.

[121] J. Toftum, B.U. Kjeldsen, P. Wargocki, H.R. Menå, E.M.N. Hansen, G. Clausen, Association between classroom ventilation mode and learning outcome in Danish schools, Build. Environ. 92 (2015) 494-503, doi:10.1016/j.buildenv. 2015.05.017.

[122] M. Griffiths, M. Eftekhari, Control of $\mathrm{CO} 2$ in a naturally ventilated classroom, Energy Build. 40 (2008) 556-560, doi:10.1016/j.enbuild.2007.04.013.

[123] N. Canha, S.M. Almeida, M.C. Freitas, M. Täubel, O. Hänninen, S.M. Almeida, M.C. Freitas, M. Täubel, O. Hänninen, Winter ventilation rates at primary schools: comparison between Portugal and Finland, 7394 (2013). 10.1080/15287394.2013.765372.

[124] P.A. and M.W. V Kukadia, Ventilation and indoor air quality in schools, BRE Environ. (2005).

[125] Z. Wang, H. Ning, X. Zhang, Y. Ji, Human thermal adaptation based on university students in China's severe cold area, Sci. Technol. Built Environ. 23 (2017) 413-420, doi:10.1080/23744731.2016.1255495.

[126] Z. Wang, A. Li, J. Ren, Y. He, Thermal adaptation and thermal environment in university classrooms and offices in Harbin, Energy Build. 77 (2014) 192-196, doi:10.1016/j.enbuild.2014.03.054.

[127] G.S. Brager, G. Paliaga, R. de Dear, Operable windows, personal control, and occupant comfort, ASHRAE Trans. 110 (2004) 17-35 2004.

[128] A. Leaman, B. Bordass, Productivity in buildings: the "killer" variables, Build. Res. Inf. 27 (1999) 4-19, doi:10.1080/096132199369615.

[129] F. Nicol, S. Roaf, Post-occupancy evaluation and field studies of thermal comfort, Build. Res. Inf. 33 (2005) 338-346, doi:10.1080/09613210500161885.

[130] M.A. Humphreys, Quantifying occupant comfort: are combined indices of the indoor environment practicable? Build. Res. Inf. 33 (2005) 317-325, doi:10. 1080/09613210500161950.

[131] N. Baker, M Standeven, A behavioural approach to thermal comfort assessment, Int. J. Sol. Energy. 19 (1997) 21-35, doi:10.1080/01425919708914329.

[132] I.A. Raja, J.F. Nicol, K.J. McCartney, M.A. Humphreys, Thermal comfort: use of controls in naturally ventilated buildings, Energy Build. 33 (2001) 235-244, doi:10.1016/S0378-7788(00)00087-6.

[133] M.A. Humphreys, H.B. Rijal, J.F. Nicol, Updating the adaptive relation between climate and comfort indoors; new insights and an extended database q, 63 (2013) 40-55. 10.1016/j.buildenv.2013.01.024. 